Accepted manuscript of Dalton Trans. 211 (2012) 13120-13131

http://doi: $10.1039 / \mathrm{c} 2 \mathrm{dt} 31189 \mathrm{e}$

\author{
Cite this: DOI: 10.1039/c0xx00000x
}

www.rsc.org/xxxxxx DD13 special issue

ARTICLE TYPE

\title{
Equilibrium, photophysical and photochemical examination of anionic lanthanum(III) mono- and bisporphyrins: the effects of the out-of-plane structure
}

\author{
Zsolt Valicsek, ${ }^{a}$ Gábor Eller, ${ }^{a}$ and Ottó Horváth ${ }^{* a}$ \\ ${ }_{5}$ Received (in $\left.X X X, X X X\right)$ Xth $X X X X X X X X X 20 X X$, Accepted Xth XXXXXXXXX 20XX \\ DOI: $10.1039 / b 000000 x$
}

Lanthanum(III) ion forms kinetically labile complexes with the 5,10,15,20-tetrakis(4-

sulfonatophenyl)porphyrin anion $\left(\mathrm{H}_{2} \mathrm{TSPP}^{4}\right)$, the compositions and formation constants of which significantly depend on the presence of potential axial ligands (at $0.01 \mathrm{M}$ ). Deviating from the chloride

10 ion, acetate coordinating to the metal center hinders the formation of bisporphyrin complex. In these

lanthanum(III) complexes, the metal center, due to its large ionic radius (103.2 pm), is located out of the

ligand plane, distorting it. Accordingly, the absorption and fluorescence spectra of these coordination compounds display special properties characteristic of the so-called sitting-atop (SAT) or out-of-plane (OOP) porphyrin complexes. Metalation significantly decreases the quantum yield of the fluorescence 15 from the $\mathrm{S}_{1}$ excited state. Quantum chemical calculations (DFT) confirm the considerable OOP displacement of the $\mathrm{La}(\mathrm{III})$ center (about $120 \mathrm{pm}$ in the monoporphyrin complexes). The monoporphyrins display efficient fluorescence $(\Phi \approx 0.03)$, while the bisporphyrin does not emit. Differing from the normal (in-plane) metalloporphyrins, excitation of these lanthanum(III) porphyrins leads to an irreversible ligandto-metal charge transfer (LMCT) followed by the opening of the porphyrin ring, which is also typical of ${ }_{20}$ OOP complexes. Dissociation releasing free-base porphyrin can also be observed upon irradiation of the monoporphyrin in acetate solution, while in the presence of chloride ions interconversions of the monoand bisporphyrins may also take place beside the irreversible photoredox reaction.

\section{Introduction}

25 Metalloporphyrins play key roles in numerous biochemical processes, such as photosynthesis and oxygen transport as well as in various redox reactions. ${ }^{1-8}$ Within this important group of compounds the so-called out-of-plane (OOP) or sitting-atop (SAT) metalloporphyrins are featured by special properties ${ }^{9-12}$ originating

30 from the non-planar structure caused by, first of all, the size of the metal center. In these complexes, the ionic radius (> 80-90 pm) of the metal center is too large to fit into the cavity of the ligand, therefore it is located above the porphyrin plane, distorting it. The symmetry of this structure is lower (generally $\mathrm{C}_{4 \mathrm{v}}$ to $\mathrm{C}_{1}$ ) than that 35 of both the free-base porphyrin $\left(\mathrm{D}_{2 \mathrm{~h}}\right)$ and the coplanar (in-plane) metalloporphyrins $\left(\mathrm{D}_{4 \mathrm{~h}}\right)$, in which the metal center fits into the ligand cavity. The rate of formation of in-plane (or normal) metalloporphyrins is much slower than that of the OOP complexes because of the rigidity of porphyrins. Larger metal ions such as ${ }_{40} \mathrm{Cd}^{2+}, \mathrm{Hg}^{2+}$, or $\mathrm{Pb}^{2+}$, however, can catalyse the formation of normal metalloporphyrins via generation of SAT complex intermediates. ${ }^{13-18}$ In these species the distortion caused by the outof-plane location of the larger metal center makes two diagonal pyrrolic nitrogens more accessible to another metal ion on the other ${ }_{45}$ side of the porphyrin ligand. ${ }^{19}$
Deviating from the coplanar metalloporphyrins, the OOP complexes, on account of their distorted structure and kinetic lability, display special photochemical properties, such as photoinduced charge transfer from the porphyrin ligand to the 50 metal center, leading to irreversible ring opening of the ligand and dissociation on excitation at both the Soret- and the Q-bands. ${ }^{20}$ The absorption and emission features of these complexes also significantly differ from those of the in-plane metalloporphyrins.

While the photoinduced behavior of normal metalloporphyrins 55 have been thoroughly studied for several decades, the investigation of OOP complexes started in this respect only in the past 8-10 years, especially in aqueous systems.

Lanthanide(III) ions offer good opportunities to examine the special photophysical and photochemical properties of OOP 60 metalloporphyrins, utilizing the well-known lanthanide contraction. Hence, they can be applied for fine tuning of the outof-plane position of the metal center in these complexes, affecting the distortion of the ligand plane and, thus, the photoinduced properties. 


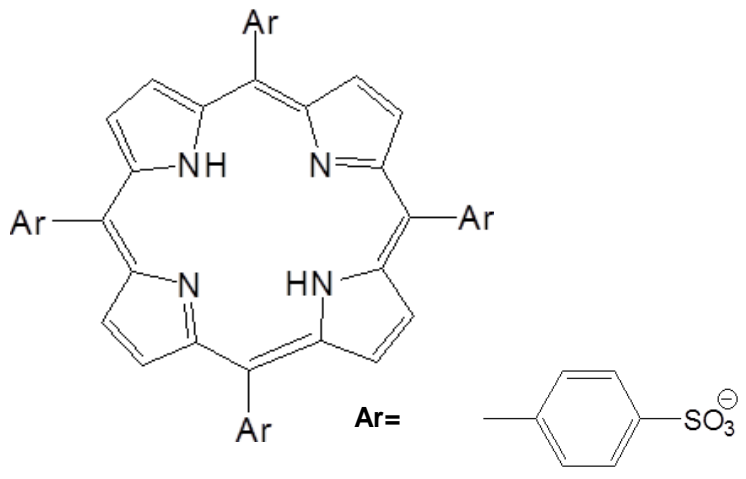

Fig. 1 The structure of 5,10,15,20-tetrakis(4-sulfonatophenyl)porphyrin $\left(\mathrm{H}_{2} \mathrm{TSPP}^{4-}\right)$.

The first paper on porphyrin complexes of lanthanide(III) ions was published in $1974 .{ }^{21}$ Initially, they were prepared as NMR probes for use in biological systems. ${ }^{22}$ They were also tested as 5 singlet oxygen producers (photosensitizers) for photodynamic therapy. ${ }^{23}$ Later on the luminescent properties of the monoporphyrin complexes of these metal ions got into the focus of examinations because the porphyrin macrocycles may sensitize the NIR emission of the lanthanide(III) center, due to their long10 lived triplet excited state. ${ }^{24,25}$

The studies of sandwich type bisporphyrin complexes of lanthanide(III) ions have been inspired that they are similar to the special reaction center of the photosynthetic bacteria. ${ }^{26}$ Even tripledecker trisporphyrins of lanthanides(III) could be prepared, mostly 15 in organic solvents. ${ }^{27,28}$ In these complexes strong $\pi \pi$ interactions were proved, and the distances of the porphyrin planes significantly depended on the ionic radius of the metal centers.

Although lanthanide(III) porphyrins have been studied in several respects, their photochemical properties have scarcely been 20 examined, especially in aqueous system. Interestingly, even in the presence of efficient electron donor $\mathrm{NADH}$, reduced nicotinamide adenine dinucleotide), not the metal center, but the porphyrin ligand $\left(\mathrm{TMPyP}^{2+}\right)$ was reduced upon irradiation of $\mathrm{Lu}(\mathrm{III}) \mathrm{TMPyP}^{5+}\left(\mathrm{H}_{2} \mathrm{TMPyP}^{4+}=\right.$ tetrakis(4-methyl-4-pyridinium)25 porphyrin). ${ }^{23}$ However, no observation was published about photoinduced CT reactions between the porphyrin and the metal center, neither dissociations of lanthanide(III) porphyrins.

On the basis of the precedents in this topic, the aim of our work, in the frame of a systematic investigation of the photophysics and 30 photochemistry of water-soluble, sitting-atop metalloporphyrins, was to study the formation and mainly the photoinduced behavior of the complexes of lanthanum(III), as the first member of the lanthanide series, with 5,10,15,20-tetrakis(4sulfonatophenyl)porphyrin (Fig 1). The effects of the presence of 35 potentially axial ligands on the formation, photophysical and photochemical properties were also examined in this work.

\section{Experimental}

\section{Materials and methods}

Analytical grade tetrasodium 5,10,15,20-tetrakis(440 sulfonatophenyl)porphyrin $\left(\mathrm{Na}_{4} \mathrm{H}_{2} \mathrm{TSPP} .12 \mathrm{H}_{2} \mathrm{O}\right.$ and $\mathrm{LaCl}_{3} .7 \mathrm{H}_{2} \mathrm{O}$ (Sigma-Aldrich) were used for the experiments. Double-distilled water purified with Millipore Milli-Q system was the solvent. All experiments were carried out with aerated systems. The solutions containing metalloporphyrin were prepared well before the 45 photophysical and photochemical experiments (keeping them at 60 ${ }^{\circ} \mathrm{C}$ for at least 3 days), so that the onset of complex equilibration was ensured. The actual concentrations of the porphyrin stock solutions prepared were checked spectrophotometrically, using the molar absorptions of the reagents at characteristic wavelengths.

${ }_{50}$ The ionic strength of each solution was adjusted to $0.01 \mathrm{M}$ by application of acetate buffer $(\mathrm{pH}=6)$ or sodium chloride. Since the applied concentration $\left(\max .6 .4 \times 10^{-4} \mathrm{M}\right.$ ) of $\mathrm{La}^{3+}$ was too low for an efficient hydrolysis, the $\mathrm{pH}$ of the solutions was not lower than 6 even in the absence of buffer. Thus, no protonation of $\mathrm{H}_{2} \mathrm{TSPP}^{4-}$ 55 could occur, according to the corresponding equilibrium constants $\left(\mathrm{pK}_{3}=4.99, \mathrm{pK}_{4}=4.76^{29}\right)$.

The molar extinction coefficients and the stability constants of the lanthanum(III) porphyrins formed were simultaneously determined according to Eqs. 1-3

60

$$
\begin{aligned}
& \mathrm{y} \mathrm{H}_{2} \mathrm{P}^{4-}+\mathrm{x} \mathrm{La}^{3+} \Leftrightarrow \mathrm{La}_{\mathrm{x}} \mathrm{P}_{\mathrm{y}}{ }^{(3 \mathrm{x}-6 \mathrm{y})}+2 \mathrm{y} \mathrm{H}^{+} \\
& \beta_{\mathrm{j}}{ }^{\prime}=\frac{\beta_{\mathrm{j}}}{\left[\mathrm{H}^{+}\right]^{2 \mathrm{y}}}=\frac{\left[\mathrm{La}_{\mathrm{x}} \mathrm{P}_{\mathrm{y}}{ }^{(3 \mathrm{x}-6 \mathrm{y})}\right]}{\left[\mathrm{H}_{2} \mathrm{P}^{4-}\right]^{\mathrm{y}}\left[\mathrm{La}^{3+}\right]^{\mathrm{x}}} \\
& \mathrm{A}_{\lambda}=1 \sum_{\mathrm{j}=1}^{\mathrm{n}} \varepsilon_{\mathrm{j} \lambda} \beta_{\mathrm{j}} \prod_{\mathrm{i}=1}^{\mathrm{k}}\left[\mathrm{c}_{\mathrm{i}}\right]^{\alpha_{\mathrm{ji}}}
\end{aligned}
$$

by fitting the calculated absorption spectra to the measured ones using MS Excel. $\varepsilon_{i, \lambda}$ is the corresponding molar absorbance at $\lambda$ 65 wavelength. Eq. 3 expresses the total absorbance of the porphyrin species (free-base and complexes) at $\lambda$. During the evaluation of the $\mathrm{A}_{\lambda} v s .\left[\mathrm{La}^{3+}\right]$ data, an iterative least-square procedure (based on Eq. 3) was used to find the best fitting values of $\beta$ ' and $\varepsilon$ parameters.

70 The apparent stability constants ( $\beta_{\mathrm{j}}{ }^{\prime}$ in Eqs. 2 and 3$)$ include the concentration of protons. The possible axial ligand (e.g. acetate) is not included explicitely because its influence on the equilibria we are interested in was constant as all conditions ( $\mathrm{pH}$, ion strength, the nature of counter-ions) were kept the same in all solutions. The 75 equilibrium constants $\beta_{\mathrm{j}}$ themselves can be calculated from the constant parameters.

\section{Instruments and procedures}

The absorption spectra were recorded and the photometric 80 titrations were monitored using a Specord S-600 diode array spectrophotometer. For the measurement of fluorescence spectra a Horiba Jobin Yvon Fluoromax-4 spectrofluorimeter was applied. Rhodamine-B and $\mathrm{Ru}(\mathrm{bpy})_{3} \mathrm{Cl}_{2}$ were used as references for correction of the detector sensitivity and for determination of the ${ }_{85}$ fluorescence quantum yields. ${ }^{30,31}$ Each compound studied was excited at the wavelength of its absorption maximum or at the isosbestic points of titrations. Luminescence spectra were corrected for detector sensitivity. The spectrum analyses were carefully carried out by fitting Gaussian curves in MS Excel. 


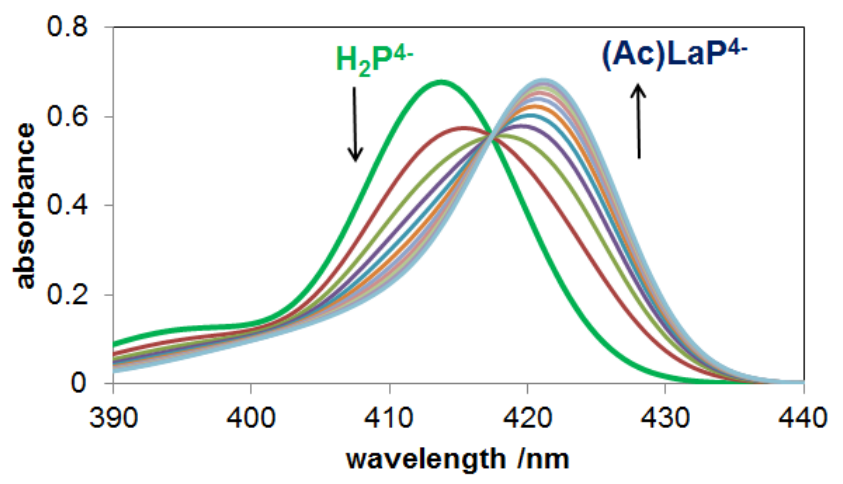

Fig. 2 Spectral changes during the reaction of $\mathrm{H}_{2} \mathrm{TSPP}^{4-}$ and lanthanum(III) ions in the presence of acetate $(0.01 \mathrm{M}) .\left(1.5 \times 10^{-6} \mathrm{M}\right.$ $\mathrm{H}_{2} \mathrm{TSPP}^{4-}$, and $0-6.4 \times 10^{-4} \mathrm{M} \mathrm{La}(\mathrm{III})$ ).

For continuous irradiations an AMKO LTI photolysis equipment (containing a 200-W Xe-Hg-lamp and a monochromator) was applied. Incident light intensity was determined with a thermopile calibrated by ferrioxalate 5 actinometry $^{32,33}\left(I_{0}=1.6-1.7 \times 10^{-5} \mathrm{M}\right.$ photon/s at $\left.421 \mathrm{~nm}\right)$. Quartz cuvettes of $1 \mathrm{~cm}$ pathlength were utilized as reaction vessels. During the irradiations the reaction mixtures were continuously homogenized by magnetic stirring. All measurements were carried out at room-temperature. The experimental results were processed 10 and evaluated by MS Excel programs on PCs.

\section{Electronic Structure Calculations}

Electronic structure calculations involved molecular geometry optimization and the determination of vertical electron excitation 15 energies. For both purposes we applied density functional theory, in particular, the B3LYP combination of functionals, ${ }^{34-36}$ and timedependent density functional. In the geometry optimizations we used the Hay-Wadt valence double-zeta (LANL2DZ) basis set ${ }^{37-39}$ in which the influence of the inner-shell electrons on the valence 20 shell is described using effective core potentials (ECP) for La. During our previous tests we found that the sulfonato-phenyl substituent has a negligible effect on the coordination site, thus in the present calculations we modeled $\mathrm{H}_{2} \mathrm{TSPP}^{4-}$ with unsubstituted porphin, $\mathrm{H}_{2} \mathrm{P}$. All calculations were performed using the Gaussian ${ }_{25} 03$ suite of programs. ${ }^{40}$

\section{Results and Discussion}

\section{Formation, Structure and Absorption Spectra}

\section{Monoporphyrin complexes}

30 Porphyrins and derivatives are the strongest light-absorbing compounds, therefore the ultraviolet-visible spectrophotometry is one of the most fundamental, yet most informative spectroscopic methods in the porphyrin chemistry. ${ }^{41}$ During the measurements the spectral changes in the ranges of both the Soret- and the Q35 bands were taken into account. The Soret-bands, the molar absorbances of which are very high (in the order of $10^{5} \mathrm{M}^{-1} \mathrm{~cm}^{-1}$ ) are in the range of $350-500 \mathrm{~nm}$, while the Q-bands appear at 500$750 \mathrm{~nm}$.

The spectra of the complexes formed in the presence of acetate 40 and chloride ions as potentially axial ligands significantly differ

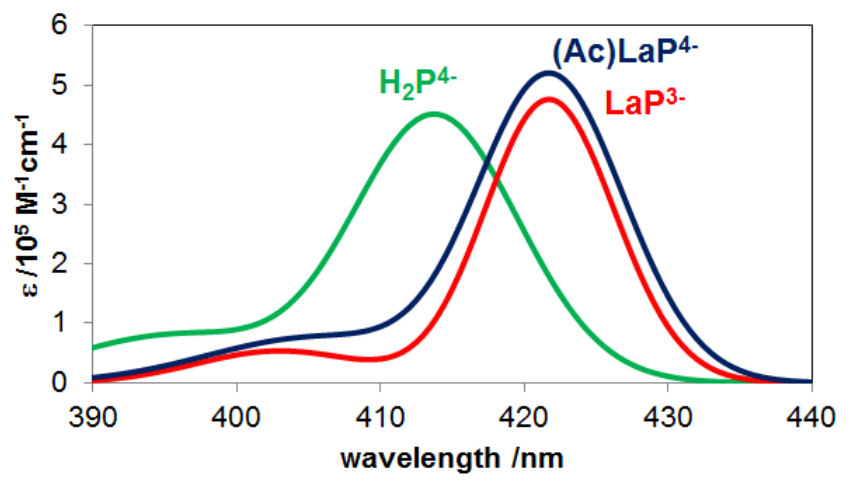

Fig. 3 Molar absorption spectra of LaTSPP $^{3-}$ in the presence of acetate $\left((\mathrm{Ac}) \mathrm{LaP}^{4-}\right)$ and chloride $\left(\mathrm{LaP}^{3-}\right.$, without the coordination of $\left.\mathrm{Cl}^{-}\right)$ compared to that of the free-base porphyrin in the range of the Soret-bands ( $0.01 \mathrm{M}$ acetate or chloride).

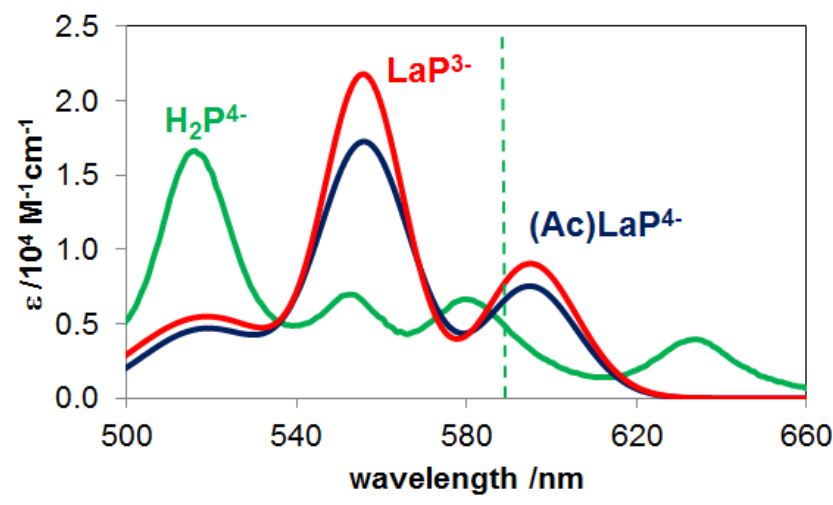

Fig. 4 Molar absorption spectra of LaTSPP ${ }^{3-}$ in the presence of acetate $\left((\mathrm{Ac}) \mathrm{LaP}^{4-}\right)$ and chloride $\left(\mathrm{LaP}^{3-}\right)$ compared to that of the free-base porphyrin in the range of the Q-bands $(0.01 \mathrm{M}$ acetate or chloride). The dotted lins represenst the average energy $\mathrm{Q}_{\mathrm{y}}(0,0)$ and $\mathrm{Q}_{\mathrm{x}}(0,0)$ of free-base porphyrins.

from each other, depending on the anions.

For determination of the compositions, stability constants, and individual absorption spectra of the complexes formed, experiments were carried out at constant porphyrin concentration, 45 changing the metal ion concentration in the range of $0-6.4 \times 10^{-4} \mathrm{M}$. Lanthanum(III) ion, as a consequence of its large ionic radius (103.2 $\mathrm{pm}^{42}$ ), forms typical out-of-plane complexes, which decreases the energy of the intraligand $\pi \pi^{*}$ transitions, i.e. causes red shift of the corresponding bands. ${ }^{20}$ The spectral changes in the 50 presence of acetate ions are shown in Fig. 2.

Evaluation of the spectra taken at both the Soret- and the Qbands were analyzed by application of Eqs. 2 and 3. The individual absorption spectra obtained through this procedure for the monoporphyrin complex in the presence of acetate and chloride 55 ions (as potentially axial ligands) are compared with that of the free base in Figs. 3 and 4, regarding the Soret- and the Q-bands, respectively. Tables 1 and 2 summarize the corresponding digital data obtained by measurements and fitting Gaussian curves.

If acetate was applied for adjustment of the ionic strength, $60 \lg \beta{ }^{\prime}{ }_{1: 1}=3.8$ was obtained for the apparent stability constant of the monoporphyrin complex (with 1:1 metal:ligand composition). The $\mathrm{La}^{3+}$ ion being a hard Lewis acid, due to the classification of Pearson, forms a relatively strong coordination bond with the 
Table 1 The Soret-absorption data of free-base and lanthanum(III) porphyrins. ${ }^{\mathrm{a}}$

\begin{tabular}{|c|c|c|c|c|}
\hline species & $\mathbf{H}_{2} \mathbf{P}^{4-}$ & $(\mathrm{Ac}) \mathbf{L a P}^{4-}$ & $\mathbf{L a P}^{3-}$ & $\mathrm{La}_{3} \mathbf{P}_{2}{ }^{6}$ \\
\hline$\lambda\{B(1,0)\} / \mathbf{n m}$ & 395 & 406 & 403 & 404 \\
\hline$\varepsilon_{\max }\{B(1,0)\} / 10^{4} M^{-1} \mathbf{c m}^{-1}$ & 8.09 & 7.05 & 5.01 & 5.52 \\
\hline$\lambda_{\text {Gauss }}\{B(\mathbf{1}, \mathbf{0})\} / \mathbf{n m}$ & 396 & 406 & 403 & 405 \\
\hline$\varepsilon_{\text {Gauss }}\{B(1,0)\} / 10^{4} M^{-1} \mathrm{~cm}^{-1}$ & 8.13 & 7.71 & 5.37 & 5.34 \\
\hline$\omega_{1 / 2}\{B(1,0)\} / \mathbf{c m}^{-1}$ & 1149 & 1130 & 851 & 1111 \\
\hline $\mathbf{f}\{\mathbf{B}(\mathbf{1}, \mathbf{0})\}$ & 0.361 & 0.340 & 0.222 & 0.245 \\
\hline$v\{\mathbf{B}(\mathbf{1}, \mathbf{0})\} / \mathbf{c m}^{-1}$ & 1090 & 936 & 1102 & 1077 \\
\hline$\lambda\{\mathbf{B}(\mathbf{0 , 0})\} / \mathbf{n m}$ & 413 & 422 & 421 & 422 \\
\hline$\varepsilon_{\max }\{B(0,0)\} / 10^{5} \mathbf{M}^{-1} \mathbf{c m}^{-1}$ & 4.66 & 5.30 & 4.89 & 4.43 \\
\hline$\lambda_{\text {Gauss }}\{B(\mathbf{0}, \mathbf{0})\} / \mathrm{nm}$ & 414 & 422 & 422 & 423 \\
\hline $\mathcal{E}_{\text {Gauss }}\{\mathrm{B}(0,0)\} / 10^{5} \mathbf{M}^{-1} \mathbf{c m}^{-1}$ & 4.45 & 5.09 & 4.76 & 4.40 \\
\hline$\omega_{1 / 2}\{\mathbf{B}(\mathbf{0}, 0)\} / \mathbf{c m}^{-1}$ & 785 & 668 & 597 & 666 \\
\hline $\mathbf{f}\{\mathbf{B}(\mathbf{0 , 0})\}$ & 1.35 & 1.31 & 1.10 & 1.13 \\
\hline $\begin{array}{l}\text { B-shift / } \mathbf{c m}^{-1} \\
\text { 2. measured wavelength: }\end{array}$ & - & $\begin{array}{l}-456 \\
\text { froms }\end{array}$ & $\begin{array}{l}-450 \\
\text { um an }\end{array}$ & -520 \\
\hline
\end{tabular}

Table 2 The Q-absorption data of free-base and lanthanum(III) porphyrins. ${ }^{a}$

\begin{tabular}{|c|c|c|c|c|}
\hline species & $\mathbf{H}_{2} \mathbf{P}^{4-} \mathbf{y}$ & $\mathbf{H}_{2} \mathbf{P}^{4-} \mathbf{x}$ & $(\mathrm{Ac}) \mathrm{LaP}^{4-}$ & $\mathbf{L a P}^{3-}$ \\
\hline$\lambda\{\mathbf{Q}(\mathbf{2}, \mathbf{0})\} / \mathbf{n m}$ & 490 & & 519 & 519 \\
\hline$\varepsilon_{\max }\{Q(2,0)\} / \mathbf{M}^{-1} \mathbf{c m}^{-1}$ & 3347 & & 4718 & 7595 \\
\hline$\lambda_{\text {Gauss }}\{\mathbf{Q}(\mathbf{2 , 0})\} / \mathrm{nm}$ & 489 & & 519 & 519 \\
\hline$\varepsilon_{\text {Gauss }}\{\mathbf{Q}(2,0)\} / \mathbf{M}^{-1} \mathrm{~cm}^{-1}$ & 3167 & & 4700 & 5500 \\
\hline$\omega_{1 / 2}\{Q(2,0)\} / \mathrm{cm}^{-1}$ & 1121 & & 1341 & 1534 \\
\hline $\mathbf{f}\{\mathbf{Q}(\mathbf{2 , 0})\}$ & 0.0137 & & 0.0255 & 0.0255 \\
\hline$v\{\mathbf{Q}(2,0)\} / \mathrm{cm}^{-1}$ & 1080 & & 1291 & 1285 \\
\hline$\lambda\{\mathbf{Q}(\mathbf{1}, \mathbf{0})\} / \mathrm{nm}$ & 516 & 579 & 556 & 556 \\
\hline$\varepsilon_{\max }\{Q(1,0)\} / M^{-1} \mathbf{c m}^{-1}$ & 16657 & 6669 & 16613 & 22425 \\
\hline$\lambda_{\text {Gauss }}\{Q(\mathbf{1}, \mathbf{0})\} / \mathrm{nm}$ & 517 & 582 & 556 & 556 \\
\hline$\varepsilon_{\text {Gauss }}\{\mathbf{Q}(\mathbf{1}, \mathbf{0})\} / \mathbf{M}^{-1} \mathbf{c m}^{-1}$ & 16062 & 6155 & 16900 & 21000 \\
\hline$\omega_{1 / 2}\{Q(1,0)\} / \mathrm{cm}^{-1}$ & 827 & 846 & 815 & 708 \\
\hline $\mathbf{f}\{\mathbf{Q}(\mathbf{1}, \mathbf{0})\}$ & 0.0513 & 0.0201 & 0.0532 & 0.0575 \\
\hline$v\{Q(1,0)\} / \mathbf{c m}^{-1}$ & 1180 & 1385 & 1176 & 1181 \\
\hline$\lambda\{\mathbf{Q}(\mathbf{0 , 0})\} / \mathrm{nm}$ & 553 & 633 & 596 & 596 \\
\hline$\varepsilon_{\max }\{Q(0,0)\} / \mathbf{M}^{-1} \mathrm{~cm}^{-1}$ & 6985 & 3980 & 7549 & 8395 \\
\hline$\lambda_{\text {Gauss }}\{\mathbf{Q}(\mathbf{0}, 0)\} / \mathbf{n m}$ & 550 & 633 & 595 & 595 \\
\hline$\varepsilon_{\text {Gauss }}\{\mathbf{Q}(0,0)\} / \mathbf{M}^{-1} \mathbf{c m}^{-1}$ & 6433 & 3676 & 7500 & 9052 \\
\hline$\omega_{1 / 2}\{\mathbf{Q}(0,0)\} / \mathrm{cm}^{-1}$ & 830 & 727 & 718 & 718 \\
\hline $\mathbf{f}\{\mathbf{Q}(\mathbf{0 , 0})\}$ & 0.0206 & 0.0103 & 0.0208 & 0.0251 \\
\hline B-Q energy gap $/ \mathrm{cm}^{-1}$ & 7174 & & 6915 & 6915 \\
\hline Q-shift $/ \mathrm{cm}^{-1}$ b & - & - & -184 & -184 \\
\hline$\varepsilon\left(\mathbf{B}_{\max }\right) / \varepsilon\left(\mathbf{Q}_{\max }\right)$ & 28.0 & & 28.7 & 21.3 \\
\hline $\mathbf{f}(\mathbf{B}) / \mathbf{f}(\mathbf{Q})$ & 14.7 & & 16.2 & 14.9 \\
\hline
\end{tabular}

${ }^{a} \lambda$, measured wavelength; $\lambda_{\text {Gauss }}$, wavelength from spectrum analysis; $\omega_{1 / 2}$, halfwidth; $f$, oscillator strength; $v$, energy of vibronic overtone; ${ }^{\mathrm{b}}$ compared to the average of the free-base's $\mathrm{Q}_{\mathrm{y}}(0,0)$ and $\mathrm{Q}_{\mathrm{x}}(0,0)$ bands.

similarly hard bidentate O-donor acetate ion (as a Lewis base), which hinders the formation of bisporphyrin complexes. This is unambiguously indicated by the clear isosbestic point in Fig. 2. Deviating from the acetate ion, the softer chloride ion coordinates

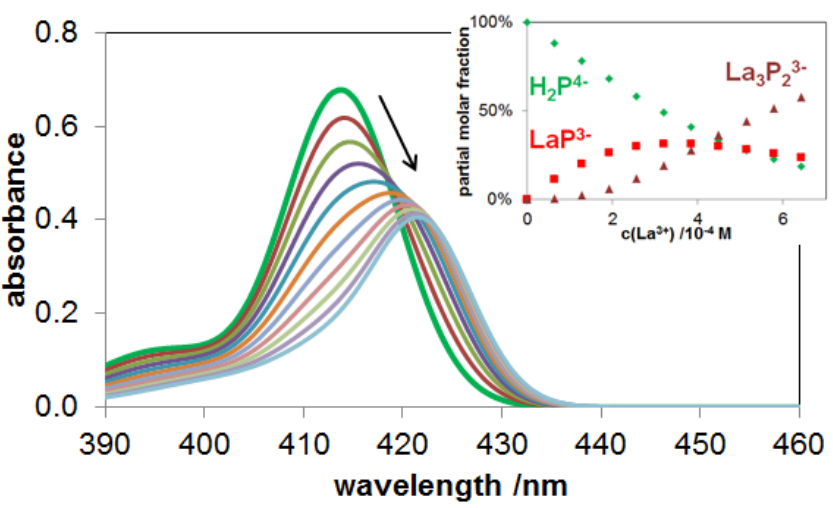

Fig. 5 Spectral changes during the reaction of $\mathrm{H}_{2} \mathrm{TSPP}^{4-}$ and lanthanum(III) ions in the presence of $0.01 \mathrm{M}$ chloride $\left(1.5 \times 10^{-6} \mathrm{M} \mathrm{H}_{2} \mathrm{TSPP}^{4-}\right.$ and $0-6.4 \times 10^{-}$ $\left.{ }^{4} \mathrm{M} \mathrm{La}(\mathrm{III})\right)$. Inset: the partial molar fractions of the species in equilibrium as functions of $\mathrm{c}\left(\mathrm{La}^{3+}\right)$.

${ }_{5}$ to $\mathrm{La}^{3+}$ much weaker, even than a water molecule does in aqueous solution. This tendency is confirmed by the composition of the lanthanum(III) chloride crystal $\left(\mathrm{LaCl}_{3} \cdot 7 \mathrm{H}_{2} \mathrm{O}\right)$. Hence, in the presence of chloride ions, i.e. in the absence of ions or molecules, which relatively strongly coordinate at axial position, the 10 formation of bis- or oligoporphyrins is possible. ${ }^{43}$ This was manifested in the spectral change upon increasing the metal concentration at constant porphyrin concentration in the presence of chloride ions (Fig. 5).

15 Electronic structure calculations were also carried out regarding the monoporphyrin complexes in this study. The main purpose of our calculations was to reveal the geometrical structure of the 1:1 lanthanum(III) porphyrins without any axial ligand $\left(\mathrm{LaP}^{+}\right)$, with acetate $((\mathrm{Ac}) \mathrm{LaP})$ or chloride $((\mathrm{Cl}) \mathrm{LaP})$ in axial position. The 20 coordination of hydroxide ion was also examined $((\mathrm{OH}) \mathrm{LaP})$ because the metal center is prone to a slight hydrolysis, e.g. at 0.1 $\mathrm{M}$ metal ion concentration the $\mathrm{pH}$ is 5.5. In the calculations, we used a model in which the sulfonato-phenyl substituents of the porphyrin ligand were omitted. Beside the geometrical structures, 25 the vertical electron excitation energies were also calculated for the Soret- and Q-bands of these monoporphyrin complexes.

According to our earlier experiences, ${ }^{44-46}$ the out-of-plane distortion of the ligand, influenced mainly by the interaction and relative size of the cavity and the metal ion, can be correctly 30 described with this model. The insertion of the $\mathrm{La}^{3+}$ ion into the porphyrin causes a considerable distortion of the macrocycle. The relative size of the metal ion as compared to the cavity of the ligand determines the magnitude of distortion.

The calculated geometrical parameters are listed in Table 3, 35 which also involves the data regarding the free base (abbreviated as $\left.\mathrm{H}_{2} \mathrm{P}\right)$ and its deprotonated form $\left(\mathrm{P}^{2-}\right)^{44,47}$ for comparison. The parameters presented are: $d(\mathrm{~N}-\mathrm{N})$, the distance between diagonally located $\mathrm{N}$ atoms, i.e. the size of the cavity; doop, the distance between the metal ion and the plane of the four $\mathrm{N}$ atoms 40 (designated as $\mathrm{N}_{4}$-plane), which is a measure of the magnitude of protrusion of the $\mathrm{La}^{3+}$ ion from the ligand; $d_{\text {dome }}$, domedness, which we define as the distance between the plane of the four $\mathrm{N}$ atoms and that of the $\beta$ carbon atoms, which characterizes the magnitude of the distortion of the macrocycle. $\delta\left(\mathrm{N}-\mathrm{C}_{\alpha}-\mathrm{C}_{\mathrm{m}}-\mathrm{C}_{\alpha}\right)$ dihedral angle 


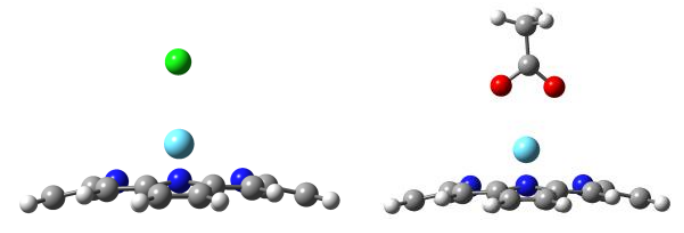

Fig. 6 The calculated structure of $\mathrm{La}(\mathrm{III})$ monoporphyrin with acetate and chloride as potentially axial ligands.

is another measure for the same purpose (distortion angle). In the case of $(\mathrm{Ac}) \mathrm{LaP},(\mathrm{Cl}) \mathrm{LaP}$, and $(\mathrm{HO}) \mathrm{LaP}$ the distance of the metal center and the axial ligand is also given ( $d$ (La-axial)).

For the sake of easier visualization the calculated structures of 5 the complexes with acetate and chloride ions in axial position are also shown (Fig. 6).

The B3LYP/LANL2DZ calculations reproduced the $\mathrm{D}_{2 \mathrm{~h}}$ structure as the most stable structure of free-base porphyrin, and, in accordance with the expectation, $\mathrm{D}_{4 \mathrm{~h}}$ symmetry for the 10 deprotonated species $\left(\mathrm{P}^{2-}\right) .^{44,47}$ The fourfold symmetry is inherited by the $\mathrm{LaP}^{+}$complex. As expected, in lanthanum(III) porphyrins the metal ion protrudes from the plane of the ligand the magnitude of which depends on the composition. The appealing explanation for this is that the diameter of $\mathrm{La}^{3+}(206.4 \mathrm{pm})$ is too large to fit 15 coplanar into the cavity of the porphyrin ring. In the $\mathrm{LaP}^{+}$complex the distance of $\mathrm{La}^{3+}$ from the $\mathrm{N}$ atoms is $241 \mathrm{pm}$, which bond length in a planar arrangement would push apart the $\mathrm{N}$ atoms to almost $482 \mathrm{pm}$, from the $420 \mathrm{pm}$ characterizing the deprotonated porphyrin. However, on the contrary, due to the lifting the $\mathrm{La}^{3+}$ ion 20 out of the plane of the $\mathrm{N}$ atoms the high strain is released so that the diagonal $\mathrm{N}-\mathrm{N}$ distance can be as small as $425 \mathrm{pm}$, which is just slightly larger than that for $\mathrm{P}^{2-}$. At the same time, the $\mathrm{La}^{3+}$ ion and the four $\mathrm{N}$ atoms form a pyramid, which induces the distortion of the plane of $\mathrm{C}_{\alpha}$ carbon tier and through it the rest of the 25 macrocycle. The protrusion of the metal center from the $\mathrm{N}_{4}$-plane is $115 \mathrm{~nm}$.

Although texaphyrins contains one more nitrogen atom in the macrocycle, compared to porphyrins, the characteristic distances in their 1:1 complexes with $\mathrm{La}(\mathrm{III})$ may be applicable for a 30 comparison with our data calculated. According to the crystallographic measurements, the average La-N distance in such a complex is $258 \mathrm{pm}$, and $d(\mathrm{OOP})$ is $91 \mathrm{pm}^{48}$ These data are in accordance with our values calculated for $\mathrm{LaP}^{+}(d(\mathrm{La}-\mathrm{N})=241 \mathrm{pm}$, $d(\mathrm{OOP})=115 \mathrm{pm})$ because the texaphyrin ring is one member 35 larger than that of the porphyrin, thus $d(\mathrm{La}-\mathrm{N})$ in its complex is longer than in $\mathrm{LaP}^{+}$. Besides, the metal center can fit better into the larger cavity of the ligand, resulting in shorter $d(\mathrm{OOP})$. The significantly smaller $\mathrm{Dy}^{3+}$ ion (with 91 pm ionic radius ${ }^{42}$ ) fits even better into the cavity of the texaphyrin ring, having an average ${ }_{40} d(\mathrm{La}-\mathrm{N})$ value of $236 \mathrm{pm}$ and a very small $d(\mathrm{OOP})(7.3 \mathrm{pm}) \cdot{ }^{49} \mathrm{In}$ the $1: 1$ porphyrin complexes of $\mathrm{Nd}^{3+}$, the size of which $(98.3 \mathrm{pm}$ ionic radius) is closer to that of $\mathrm{La}^{3+}, d(\mathrm{Nd}-\mathrm{N})$ was determined to be $245 \mathrm{pm} .{ }^{50}$ Since these complexes contained a tripodal axial ligand (a phosphite derivative) pulling the metal center out of the 45 cavity, the value of $d(\mathrm{OOP})$ in these cases was measured to be 130 $\mathrm{pm}$. These data are in very good agreement with our values calculated for $(\mathrm{Cl}) \mathrm{LaP},(\mathrm{Ac}) \mathrm{LaP}$, and $(\mathrm{OH}) \mathrm{LaP}(d(\mathrm{La}-\mathrm{N})=247-250$ $\mathrm{pm}, d(\mathrm{OOP})=125-129 \mathrm{pm})$, indicating the reliability of the
Table 3 The structural data calculated for the monoporphyrin of $\mathrm{La}^{3+}$ with $\mathrm{TSPP}^{6-}$ and also with various anions in axial position compared to those of the free-base porphyrin $\left(\mathrm{H}_{2} \mathrm{TSPP}^{4-}=\mathrm{H}_{2} \mathrm{P}\right)$ and its deprotonated form $\left(\mathrm{P}^{2-}\right)$. Explanation of the types of data are given in the text.

\begin{tabular}{ccccccc}
\hline species & $\mathbf{H}_{2} \mathbf{P}$ & $\mathbf{P}^{2-}$ & $\mathbf{L a P}^{+}$ & $(\mathbf{C l}) \mathbf{L a P}$ & $(\mathbf{A c}) \mathbf{L a P}$ & $(\mathbf{H O}) \mathbf{L a P}$ \\
\hline symmetry & $\mathrm{D}_{2 \mathrm{~h}}$ & $\mathrm{D}_{4 \mathrm{~h}}$ & $\mathrm{C}_{4 \mathrm{v}}$ & $\mathrm{C}_{4 \mathrm{v}}$ & $\mathrm{C}_{1}{ }^{\mathrm{b}}$ & $\mathrm{C}_{\mathrm{s}}$ \\
$d(\mathrm{La}-\mathrm{N}) / \mathrm{pm}$ & $102^{\mathrm{c}}$ & - & 241 & 247 & 247 & 250 \\
$d(\mathrm{~N}-\mathrm{N}) / \mathrm{pm}$ & 407,425 & 420 & 425 & 427 & 426 & 428 \\
$d(\mathrm{OOP}) / \mathrm{pm}$ & - & - & 115 & 125 & 125 & 129 \\
$d($ dome $) / \mathrm{pm}$ & - & - & 50 & 52 & 56 & 55 \\
$d($ La-axial $) / \mathrm{pm}$ & - & - & - & 278 & 262 & 223 \\
$\delta\left(\mathrm{N}-\mathrm{C}_{\alpha}-\mathrm{C}_{\mathrm{m}}-\mathrm{C}_{\alpha}\right) /{ }^{\circ}$ & 0 & 0 & 6.03 & 6.27 & 6.51 & 6.69 \\
\hline
\end{tabular}

${ }^{\text {a This }} \mathrm{C}_{1}$ symmetry is very close to $\mathrm{C}_{\mathrm{s}}$ because the axial ligands are not totally in the direction of axial axis, perpendicular to the plane of pyrrol-nitrogens. ${ }^{\mathrm{b}} d(\mathrm{H}-\mathrm{N})$

geometric data obtained in our study.

50 These results are similar to those obtained for the $\mathrm{BiP}^{+}$ complex, ${ }^{46}$ but, interestingly, in that case, $d(\mathrm{OOP})$ was only $88 \mathrm{pm}$, although the radius of $\mathrm{Bi}^{3+}(103 \mathrm{pm})$ is about the same as that of $\mathrm{La}^{3+}(103.2 \mathrm{pm})$. This phenomenon indicates that $\mathrm{Bi}^{3+}$, probably due to its softer Lewis acid character, has a stronger interaction 55 with the porphyrin ligand, leading to a deeper insertion into the cavity of the ligand. A similar phenomenon was observed for the even softer Lewis acid $\mathrm{Hg}^{2+}$ (with $102 \mathrm{pm}$ radius), in the case of which $d(\mathrm{OOP})$ was as small as $55 \mathrm{pm} .{ }^{44}$ In the latter complex the deeper insertion of the metal center into the cavity of the ligand 60 moderately pushes apart the $\mathrm{N}$ atoms, resulting in the diagonal $\mathrm{N}$ $\mathrm{N}$ distance of $436 \mathrm{pm}$.

The macrocycle distortion from the planar structure is characterized by domedness ( $d$ (dome) ) values of $53 \pm 3 \mathrm{pm}$ for the lanthanum(III) porphyrins. In accordance with the corresponding 65 values of $d(\mathrm{OOP})$, these data are considerably larger than those for the $\mathrm{HgP}$ and $\mathrm{BiP}^{+}$complexes (40 and $38 \mathrm{pm}$, respectively). ${ }^{44,46} \mathrm{As}$ the spectral, photophysical and photochemical properties of several OOP porphyrins are very similar, it would be reasonable to assume that the common property, the doming is the determining 70 source of those.

The axial ligands moderately increase the $d(\mathrm{OOP})$, with about $10 \pm 4$ pm (i.e., less than $10 \%$ ), and $d$ (dome), with a similar percentage. The $\mathrm{M}$-axial distances are in very good agreement with those obtained for the corresponding Bi(III) complexes. ${ }^{46}$ They are 75 just about $5 \%$ higher than the individual values of $d$ (M-axial) for the bismuth(III) porphyrins, due to the weaker interaction as a consequence of the harder Lewis acid character of lanthanum(III).

On the basis of the very weak interactions between the axial ligands and the metal center we can expect that coordination of 80 acetate or chloride ions hardly modifies the absorption properties. This has been confirmed by the absorption spectra shown in Figs. 3 and 4. Chloride ion coordinates more weakly to $\mathrm{La}^{3+}$ than acetate ion does, as clearly indicated by the formation of bis- or oligoporphyrins in the previous case as shown by the spectral 85 change in Fig. 5. We have observed similar phenomena in the corresponding systems with cerium(III), neodymium(III), and samarium(III). ${ }^{51}$ In these cases, especially at a relatively low chloride concentration $(0.01 \mathrm{M})$, the axial positions are occupied mostly by water (as solvent) molecules. Although the axial 90 coordination of acetate to $\mathrm{La}^{3+}$ is strong enough to hinder the 


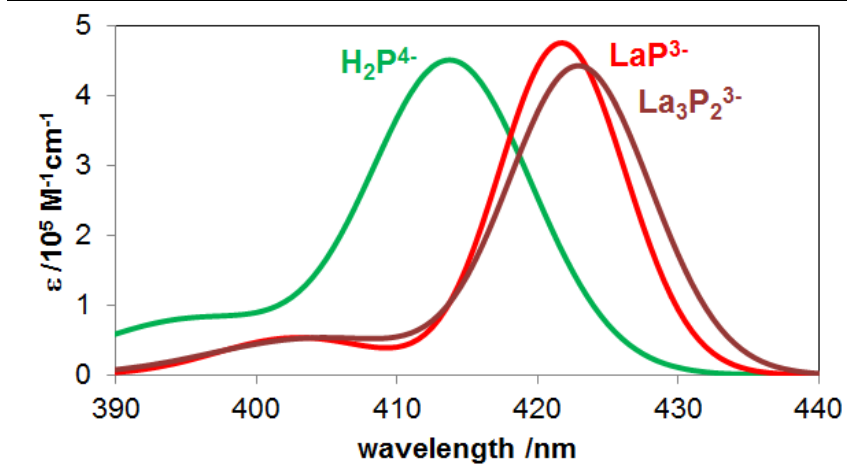

Fig. 7 Molar absorption spectra of mono- and bisporphyrins in the presence of $0.01 \mathrm{M}$ chloride, compared to that of the free-base porphyrin in the range of the Soret-bands.
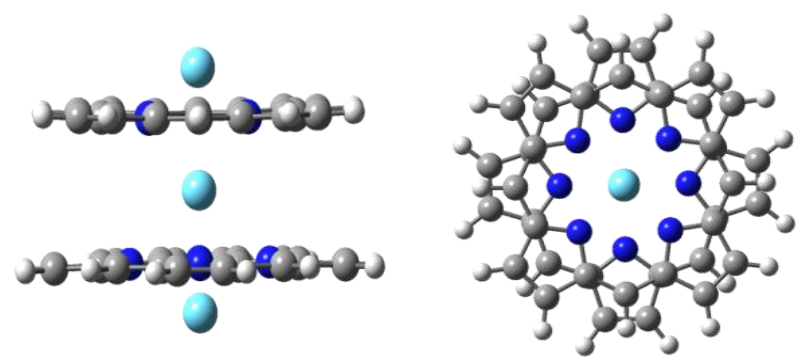

Fig. 8 The structure of the 3:2 lanthanum(III) porphin calculated at the B3LYP/LANL2DZ level of theory (side- and top views).

Table 4 Calculated absorption data of unsubstituated free-base, deprotonated and lanthanum(III) porphyrin with potential axial ligands.

\begin{tabular}{|c|c|c|c|c|c|c|}
\hline \multirow{2}{*}{$\begin{array}{c}\text { species } \\
\text { transition-symmetry }\end{array}$} & \multicolumn{2}{|c|}{$\mathbf{H}_{2} \mathbf{P}$} & \multirow{2}{*}{$\begin{array}{l}\mathbf{P}^{2-} \\
\mathrm{E}_{\mathrm{U}}\end{array}$} & \multirow{2}{*}{$\begin{array}{c}\mathbf{L a P}^{+} \\
\mathrm{E}\end{array}$} & \multirow{2}{*}{$\begin{array}{c}\text { (Cl)LaP } \\
\mathrm{E}\end{array}$} & \multirow{2}{*}{$\begin{array}{c}(\text { HO)LaP } \\
y=A^{\prime}, x=A^{\prime \prime}\end{array}$} \\
\hline & $\mathrm{y}=\mathrm{B}_{2 \mathrm{u}}$ & $\mathrm{x}=\mathrm{B}_{1 \mathrm{u}}$ & & & & \\
\hline$\lambda(\mathrm{B}) / \mathrm{nm}$ & 357 & 378 & 390 & 358 & 365 & 363 \\
\hline $\mathrm{f}(\mathrm{B})$ & 0.579 & 0.356 & 1.33 & 0.7923 & 0.6499 & 0.7050 \\
\hline B-shift $/ \mathrm{cm}^{-1}$ & & & -1551 & 677 & 159 & 294 \\
\hline$\lambda(\mathrm{Q}) / \mathrm{nm}$ & 511 & 553 & 606 & 512 & 521 & 524 \\
\hline$f(Q)$ & 0.00030 & 0.00240 & 0.0492 & 0.00030 & 0.00000 & 0.00010 \\
\hline Q-shift $/ \mathrm{cm}^{-1}$ & & & -2296 & 708 & 360 & 259 \\
\hline
\end{tabular}

The shifts were calculated from the average of $\mathrm{y}$ and $\mathrm{x}$ transitions of the free-base porphyrin; $f$ is the oscillator strength.

formation of bisporphyrins, it very slightly influences the absorption features of the porphyrin complex. It practically does not change the energy of the electronic transitions in the ranges of either the Soret- or the Q-bands. This is in accordance with the fact 5 that these transitions are of intraligand character and the distortion of the porphyrin ring is hardly modified by the interaction with this anion. Only the intensities of the Q-bands are appreciably decreased (Fig. 4).

Electronic structure calculations were also carried out for 10 determination of the vertical excitation energies, i.e. the energies of the Soret- and Q-bands, for the monoporphyrin complexes. The results of these calculations are summarized in Table 4. As the data indicate, the absolute values calculated for both the Soret- and the Q-bands are rather close to the measured ones. However, the shifts 15 due to the metalation of the free-base porphyrin deviates from the experimentally observed tendency. This may be accounted for that these bands, according to our calculations, were not found to be pure one-electron excitations but mixtures of them, often with several one-electron excitations superposed with comparable 20 weight; in other words, configuration interaction is essential here. Notably, the bands calculated for the deprotonated porphyrin display considerable red shifts (which were experimentally observed for the metalloporphyrins). This phenomenon can be interpreted as follows: in the deprotonated porphyrin all four 25 pyrrol-nitrogens can take the same proportion in the delocalization, while the diagonally placed pairs of pyrrols are different in the free-base (twice protonated) porphyrin. The deprotonation increases aromatization, resulting in the bathochromic effect of the spectrum. This result suggests that in an out-of-plane complex the 30 electronic properties of macrocycle approach that of $\mathrm{P}^{2-}$. The potential axial ligands slightly decrease the band energies compared to those of $\mathrm{LaP}^{+}$, due the increased out-of-place distance of the metal center, and, thus, the slightly increased dome distortion (see in Table 3). Experimentally it is not observable 35 because of the coordination of water molecules.

\section{Bisporphyrin complex}

As indicated earlier, and also observed in similar aqueous systems with other lanthanide(III) ions, chloride ions coordinate to 40 the metal center $\left(\mathrm{La}^{3+}\right)$ in axial position more weakly than the solvent molecule does. Thus, more complicated bis- or oligoporphyrin complexes may be formed. Such reactions can be accounted for the high coordination number ( 8 and 9 ), which is peculiar to the ions of the $f$-block elements. In the bisporphyrin 45 complexes the tetradentate ligands generate coordination spheres with 8 position around the metal center with cubic (CU-8) or square antiprism (SAPR-8) symmetry. Although the difference between the stabilities of these two structures is relatively small, the latter one is more characteristic of these complexes. As shown 50 in Fig 5, upon increasing the concentration of the metal ion $\left(\mathrm{La}^{3+}\right)$ at constant porphyrin concentration in the presence of chloride, no isosbestic point can be observed in the series of absorption spectra. This spectral change clearly indicates that the increasing concentration of the monoporphyrin complex is accompanied by 55 the appearance of bis- or, much less probably at these concentrations, oligoporphyrins. Thus, deviating from the corresponding system containing acetate, beside the red shift of the Soret-band (compared to that of the free base), a decrease of the absorbance can be observed - to about half that of the 60 monoporphyrin (which is very similar to the absorbance of the free base). This phenomenon suggests that the molar absorbance of the bisporphyrin formed is about the same as that of the 
monoporphyrin as proved by the individual spectrum determined (Fig. 7). The same tendency was observed in the case of mono- and bisporphyrins of $\mathrm{Hg}(\mathrm{II})$ with $\mathrm{TSPP}^{6-}$. $^{44}$ The formation of bisporphyrin is also confirmed by the slight broadening of the 5 Soret-band. The results of the photochemical reactions of these species also confirm the formation of bisporphyrin (see later). Theoretically the composition of this bisporphyrin may be $2: 2$ or 3:2 (metal:ligand). However, for the 2:2 composition, as experienced in the case of the corresponding $\mathrm{Hg}$ (II) porphyrins, ${ }^{44}$ 10 the electronic calculation cannot provide a well-defined structure. This constitution corresponds to two 1:1 complexes which proved to be bound together by relatively weak intermolecular forces. As the 1:1 monomers are not planar, several relative arrangements can be assumed. The dimerization energies were close to each other, 15 independently of the arrangement of the metal ions and ligands.

Contrary to these structures, in the case of the 3:2 composition the distance between the porphyrin planes is shorter than in any of the 2:2 arrangements because in this symmetric complex (Fig. 8) the central metal is equally bound to both macrocyclic ligands, 20 while in the 2:2 species it is asymmetrically coordinated. This clearly indicates that the 3:2 composition provides a more stable arrangement than any of the 2:2 types does. The direct ligandligand (stacking) interaction in the latter cases is much weaker anyway due to the distorted planes.

25 As shown in Fig. 8, in the 3:2 structure two porphyrin rings sandwich one $\mathrm{La}(\mathrm{III})$ ion, and there are two $\mathrm{La}(\mathrm{III})$ ions coordinated to the outer side of both porphyrins. The three $\mathrm{La}$ (III) ions are located along the same straight line which is also a $C_{2}$ and $\mathrm{S}_{4}$ symmetry axis of the complex. Because of the coordination on 30 both sides, the ligand is almost planar (the domedness is less than $10 \mathrm{pm})$. The two porphyrin rings are rotated by $45^{\circ}$ with respect to each other around the axis formed by the $\mathrm{La}(\mathrm{III})$ ions so that the overall symmetry of the complex is $D_{4 d}$. The outer La(III) ions protrude almost twice as much as in the 1:1 complex.

35 Beside the structural considerations, also according to the calculations of the equilibria on the basis of the spectral changes, the $3: 2$ composition proved to be much more stable than the $2: 2$ species. These calculations provided the following formation constants for the $1: 1$ and 3:2 complexes in the presence of chloride 40 ions: $\lg \beta{ }^{\prime}{ }_{1: 1}=3.3$ and $\lg \beta{ }^{\prime}{ }_{3: 2}=15.9$. The stability constant for the $1: 1$ species in the presence of acetate is about half order of magnitude higher $\left(\lg \beta{ }_{1: 1}^{\prime}=3.8\right)$, which may be attributed to the trans effect of the axial ligand. A similar phenomenon was observed in the case of cadmium(II) porphyrins with $\mathrm{HO}^{-}$as axial ligand. ${ }^{45}$ Comparing 45 the previous stability constants to those of the corresponding $\mathrm{Hg}$ (II) complexes $\left(\lg \beta{ }^{\prime}{ }_{1: 1}=6.0\right.$ and $\left.\lg \beta^{\prime}{ }_{3: 2}=18.5^{44}\right)$, the latter ones are almost 3 orders of magnitude higher, although the size of the metal ions are very similar (103.2 and $102 \mathrm{pm}$ for $\mathrm{La}^{3+}$ and $\mathrm{Hg}^{2+}$, respectively). This may be the consequence of the harder Lewis 50 acid character of the lanthanum(III) ion, which results in a more stable aqua complex and a less stable metalloporphyrin (with the softer Lewis base $\mathrm{N}$-donor macrocycle) than in the case of the softer mercury(II) ion.

\section{${ }_{55}$ Emission}

As Fig. 9 shows, coordination of the metal ion to the porphyrin ligand results in a strong blue shift of the emission bands and a

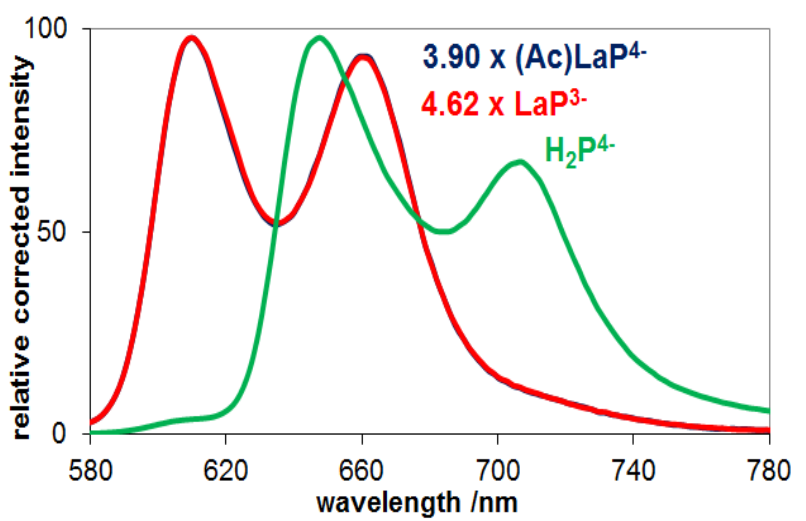

Fig. $9 \mathrm{~S}_{1}$-fluorescence spectra of the 1:1 lanthanum(III) porphyrin in the presence of acetate $\left((\mathrm{Ac}) \mathrm{LaP}^{4-}\right)$ and chloride $\left(\mathrm{LaP}^{3-}\right)$ compared to that of the corresponding free-base $\left(\mathrm{H}_{2} \mathrm{TSPP}^{4-}\right)$ upon excitation at the isosbestic point in the titrations spectral series $(418 \mathrm{~nm})$.

significant decrease of the fluorescence intensity (i.e. quantum yield) in the case of the monoporphyrin in both systems.

60 The characteristic data for the $S_{1}$-fluorescence of the monoporphyrins compared to those of the corresponding free base are summarized in Table 5. The hypsochromic effect in the fluorescence, i.e. the shift of the $(0,0)$ band (by $\left.911 \mathrm{~cm}^{-1}\right)$, is in contrast with the red shift in the absorption. This blue shift-red 65 shift anomaly, however, is virtual, because the absorption shift is referred to the average of the $\mathrm{Q}_{y}(0,0)$ - and $\mathrm{Q}_{x}(0,0)$-bands of the free-base ligand, while the emission derives not from a hypothetical average level, but from the energetically lower $\mathrm{S}_{1 x^{-}}$ state (populated in $\mathrm{Q}_{x}(0,0)$ absorption). ${ }^{45}$

70 Both phenomena indicate that the structure of the originally flat (free-base) ligand is distorted in these metalloporphyrins. The metalation significantly diminishes the quantum yield (from (from 0.075 to $0.023-0.027$ ) because the distortion of the ligand promotes other energy dissipation processes than light emission. Similar 75 tendencies of the band-shifts and quantum yields were observed in the fluorescence of typical OOP metalloporphyrins such as $\mathrm{Hg}$ (II)TSPP ${ }^{4-}, \quad\left(\mathrm{Hg}(\mathrm{I})_{2}\right)_{2} \mathrm{TSPP}^{2-}, \quad \mathrm{Cd}(\mathrm{II}) \mathrm{TSPP}^{4-}, \quad$ Bi(III)TSPP ${ }^{3-}$, $\mathrm{Tl}(\mathrm{I})_{2} \mathrm{TSPP}^{4-}$ or $\mathrm{Fe}(\mathrm{II}) \mathrm{TSPP}^{4-}{ }^{44-47,52-55}$ This feature, in accordance with the characteristics of the absorption spectra, confirms that $80(\mathrm{Cl}) \mathrm{LaP}$ and $(\mathrm{Ac}) \mathrm{LaP}$ are of sitting-atop or out-of-plane type.

Since excitation at both the Soret- and the Q-bands leads to the same emission spectrum in the 580-780-nm range, the fluorescence takes place from the same excited state $\left(S_{1}\right)$, i.e. excitation to the $S_{2}$ state is followed by an efficient internal 85 conversion to the $S_{1}$ state. The efficiency of the IC can be determined from the fluorescence quantum yields measured at the Soret- and the Q-bands (Table 5). The value of $\Phi_{\mathrm{IC}}$ is about 0.75 for the free base, while metalation diminishes it to 0.59 . The significant decrease of the quantum yield upon metalation is 90 predominantly the result of the more efficient nonradiative decay. This strongly diminishes the fluorescence lifetime, too, as observed for other 1:1 OOP complexes of this anionic porphyrin, e.g. with $\mathrm{Bi}^{3+},{ }^{46} \mathrm{Cd}^{2+},{ }^{45}$ or $\mathrm{Hg}^{2+} .{ }^{44}$ Although it was not measured in this work, an estimation could be made by using the Strickler-Berg 95 equation. ${ }^{56}$ According to this calculation, metalation decreases the lifetime to about one order of magnitude lower value (Table 5).

The bisporphyrin did not show any fluorescence, neither upon 
excitation at the Soret- nor at the Q-bands. This is in accordance with the observation in the case of the anionic bisporphyrins of $\mathrm{Hg}(\mathrm{II}){ }^{44}$ The lack of emission from the bisporphyrins may be attributed to their complicated structure, promoting more effective 5 vibronic decays. Besides, as suggested in the case of $\mathrm{Ce}(\mathrm{IV})(\mathrm{OEP})_{2}$ $(\mathrm{OEP}=$ octaethylporphyrin $)$, the importance of neutral $\left(\pi, \pi^{*}\right)$ exciton states of the two rings, ring-to-ring charge-transfer states and ring-to-metal charge-transfer states may also play important roles in quenching fluorescence in this sandwich complex. ${ }^{57}$

\section{${ }_{10}$ Photochemistry}

The in-plane (normal) metalloporphyrins do not undergo efficient photoinduced LMCT reactions as a consequence of their kinetically stable, planar structure. The out-of-plane complexes, however, display a characteristic photoredox chemistry featured by 15 irreversible photodegradation of the porphyrin ligand. ${ }^{20,44-47}$ This photochemical behavior is caused by the efficient separation of the reduced metal center and the oxidized macrocycle, following the

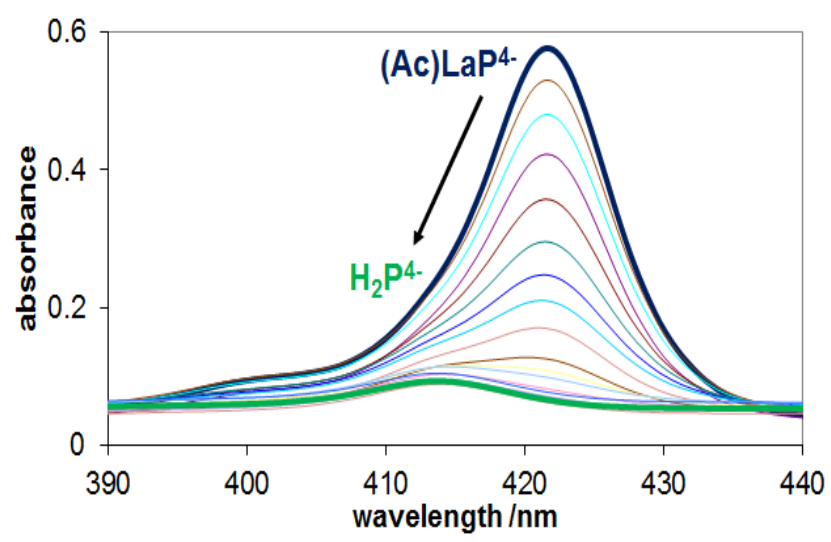

Fig. 10 Spectral changes during the Soret-band irradiation of the 1:1 lanthanum(III) porphyrin in the presence of $0.01 \mathrm{M}$ acetate. $\left(1.47 \times 10^{-6}\right.$ $\mathrm{M} \mathrm{H}_{2} \mathrm{TSPP}^{4-}, 6.4 \times 10^{-6} \mathrm{M} \mathrm{La}^{3+}, \mathrm{pH} \approx 6, I_{0}(421 \mathrm{~nm})=1.44 \times 10^{-5} \mathrm{M}$ photon $/ \mathrm{s}, \ell=1 \mathrm{~cm})$.

Table 5 Characteristic $\mathrm{S}_{1}$-fluorescence data of the 1:1 lanthanum(III) porphyrin in the presence of acetate (( $\left.\left.\mathrm{Ac}\right) \mathrm{LaP}^{4-}\right)$ and chloride $\left(\mathrm{LaP}^{3-}\right) \mathrm{compared}$ to that of the corresponding free-base $\left(\mathrm{H}_{2} \mathrm{P}^{4-}\right){ }^{\mathrm{a}}$

\begin{tabular}{|c|c|c|c|c|c|c|c|c|c|c|}
\hline \multirow{2}{*}{$\begin{array}{c}\text { species } \\
\text { transition }\end{array}$} & \multicolumn{4}{|c|}{$\mathbf{H}_{2} \mathbf{P}^{4-}$} & \multicolumn{3}{|c|}{ (Ac) $\mathrm{LaP}^{4-}$} & \multicolumn{3}{|c|}{$\mathbf{L a P}^{3-}$} \\
\hline & \multicolumn{2}{|c|}{$S_{1}(0,0)$} & \multirow{2}{*}{$\begin{array}{c}\mathbf{S}_{\mathbf{1}}(\mathbf{0 , 1}) \\
705\end{array}$} & \multirow{2}{*}{$\frac{\mathbf{S}_{\mathbf{1}}(\mathbf{0 , 2})}{780}$} & \multirow{2}{*}{$\frac{S_{1}(\mathbf{0 , 0})}{611}$} & \multirow{2}{*}{$\frac{S_{1}(\mathbf{0 , 1})}{659}$} & \multirow{2}{*}{$\begin{array}{c}\mathbf{S}_{\mathbf{1}}(\mathbf{0 , 2}) \\
714\end{array}$} & \multirow{2}{*}{$\begin{array}{r}\mathbf{S}_{\mathbf{1}}(\mathbf{0 , 0}) \\
611\end{array}$} & \multirow{2}{*}{$\frac{\mathbf{S}_{\mathbf{1}}(\mathbf{0 , 1})}{659}$} & \multirow{2}{*}{$\begin{array}{c}\mathbf{S}_{\mathbf{1}}(\mathbf{0 , 2}) \\
713\end{array}$} \\
\hline$\lambda\left\{\mathbf{S}_{\mathbf{1}}(\mathbf{0}, \mathbf{i})\right\}$ & $\mathrm{nm}$ & 647 & & & & & & & & \\
\hline $\mathbf{I}_{\max }(\mathbf{0 , i}) / \mathbf{I}_{\operatorname{ma}}$ & $(0,0)$ & - & 0.712 & 0.0527 & - & 0.937 & 0.089 & - & 0.928 & 0.090 \\
\hline$\omega_{1 / 2}\left\{\mathbf{S}_{1}(\mathbf{0}, \mathbf{i})\right.$ & $/ \mathrm{cm}^{-}$ & 828 & 1065 & 1005 & 778 & 919 & 858 & 782 & 918 & 865 \\
\hline$\phi\left\{\mathbf{S}_{1}(\mathbf{0}, \mathbf{i})\right\}$ & $10^{-2}$ & 3.81 & 3.49 & 0.243 & 1.24 & 1.38 & 0.12 & 1.05 & 1.14 & 0.10 \\
\hline$v\left\{\mathbf{S}_{1}(\mathbf{0}, \mathbf{i})\right\}$ & $\mathrm{m}^{-1}$ & - & 1197 & 1342 & - & 1183 & 1166 & - & 1181 & 1153 \\
\hline S $_{1}$-Stokes/ & $m^{-1}$ & & 360 & & & & 448 & & 451 & \\
\hline$S_{1}$-shift /c & & & - & & & & 888 & & 886 & \\
\hline$\phi\left(\mathbf{S}_{1}\right) / \mathbf{1 0}$ & & & $7.53(6$ & & & & 2.74 & & 2.30 & \\
\hline$\Phi\left(\mathbf{S}_{1}-\mathbf{B}\right) /$ & & & 5.62 & & & & 1.62 & & 1.37 & \\
\hline$\phi(\mathbf{I C})$ & & & 0.746 & & & & 0.591 & & 0.598 & \\
\hline$\tau\left(\mathbf{S}_{1}\right) / \mathbf{n}$ & & & 10.03 & & & & $0.97^{c}$ & & $0.70^{c}$ & \\
\hline $\mathbf{k}_{\mathrm{r}}\left(\mathrm{S}_{1}\right) / \mathbf{1 0}$ & & & 7.51 & & & & & & & \\
\hline $\mathbf{k}_{\mathrm{nr}}\left(\mathrm{S}_{\mathbf{1}}\right) / \mathbf{1 0}$ & & & 9.22 & & & & & & & \\
\hline $\begin{array}{l}k_{\mathrm{r}}(\text { Strick } \\
\text { Berg) } / 10 \\
\end{array}$ & & & 8.15 & & & & 28.4 & & 32.8 & \\
\hline
\end{tabular}

ligand-to-metal charge-transfer reaction, which finally leads to irreversible ring cleavage of the porphyrin ligand, giving open20 chain dioxo-tetrapyrrol derivatives, bilindions. The same type of main end-product was observed for the photo-oxygenation of Tl(I) and $\mathrm{Mg}(\mathrm{II})$ meso-tetraphenylporphyrin, ${ }^{58,59}$ besides, for the chemical oxidation of the analogous $\mathrm{Zn}$ (II) complex. ${ }^{60}$ Nevertheless, as minor end-product other types of oxidized 25 derivatives of porphyrins may also be formed, but in all of them the extended conjugation of the double bonds are ceased as the drastic spectral changes indicate.

The irradiations of the lanthanum(III) porphyrins were carried out at the Soret-bands, in aerated systems. As Fig. 10 displays, the 30 photoredox degradation of the ligand is accompanied by a less efficient dissociation to the free base and the lanthanum(III) ion. This is the consequence of the lability of the out-of-place complexes as observed in the case of $\mathrm{Bi}(\mathrm{III}),{ }^{46} \mathrm{Hg}(\mathrm{II}),{ }^{44}$ and $\mathrm{Cd}(\mathrm{II})^{45}$ porphyrins, too. Keeping the irradiated solution in the dark
35 for a week, the released free-base porphyrin converted to the $1: 1$ complex again (Fig. 10). This phenomenon clearly indicates the reversibility of the dissociation; a new equilibrium was reached, according to the actual concentrations of the porphyrin ligand and the metal ion.

40 One may expect that in the case of such a photoinduced LMCT process the efficiency predominantly depends on the redox potential of the metal center (with a given porphyrin ligand). However, our previous observations clearly indicated that its size (and, thus, its out-of-plane position) is the determining factor in 45 this respect, ${ }^{20}$ promoting the dissociation of the reduced metal center. Accordingly, the quantum yields for the photoredox degradation of $\mathrm{Tl}(\mathrm{I})_{2} \mathrm{TSPP}^{4-}$ were more than one order of magnitude higher than those (under similar conditions) for the reaction of $\mathrm{Tl}(\mathrm{III}) \mathrm{TSPP}^{3-} \cdot{ }^{55,52}$ Moreover, the in-plane 50 metalloporphyrin $\mathrm{Fe}(\mathrm{III}) \mathrm{TSPP}^{3-}$ does not display any photoredox degradation, while the corresponding $\mathrm{Fe}$ (II) complex (of OOP 


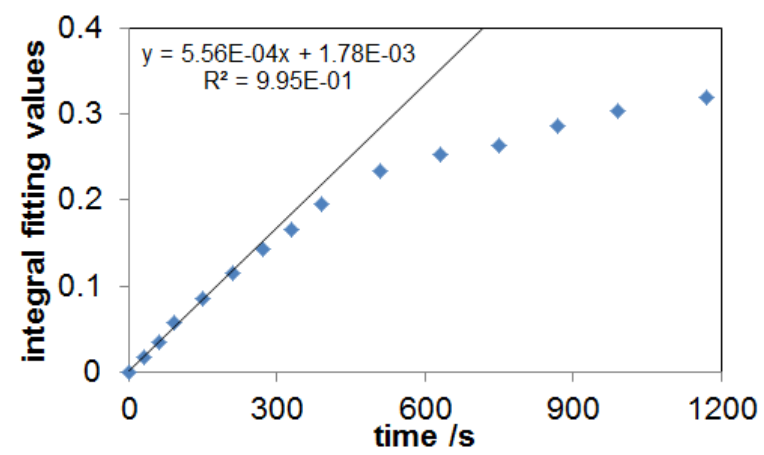

Fig. 11 The integral fitting method applied to spectral changes in Fig. 10. The values of the $y$ coordinates are calculated with the right side of Eq. 7 . After $400 \mathrm{~s}$, the points deviate from the linear.

character) efficiently undergoes such a reaction. ${ }^{53,54}$ Although $\mathrm{La}^{2+}$ could not be detected in our system, due to its low concentration and high reactivity (it may reduce even hydrogen from water), in the case of the analogous $\mathrm{Hg}(\mathrm{II})$ porphyrins 5 formation of $\mathrm{Hg}_{2}{ }^{2+}$ as an end-product was observed. ${ }^{44,61}$ The photoinduced reduction of the $\mathrm{Tl}^{3+}$ center in $\mathrm{Tl}(\mathrm{III}) \mathrm{TSPP}^{3-}$, giving stable $\mathrm{Tl}^{+}$, could also be proved. ${ }^{52}$

In simple cases the initial slope method can be used for determination of the quantum yield of a photochemical reaction. It 10 is based on Eq. 4 expressing the change in the concentration of the absorbing species during the photolysis results in a change of light absorption:

$$
I_{0} \Phi\left(1-10^{-A}\right)=\frac{\Delta c}{\Delta t}=-\frac{\Delta A}{\varepsilon l \Delta t}{ }^{15}
$$

where $I_{0}$ is the concentration of incident photons in the cuvette per second $\left(\mathrm{mol} \mathrm{dm} \mathrm{dm}^{-3} \mathrm{~s}^{-1}\right) ; \Phi$ is the overall photochemical quantum yield; $A$ is the absorbance at the wavelength of irradiation; $\Delta c / \Delta t$ is 20 the reaction rate, i.e. the change in concentration per seconds (decrease for the starting compounds, increase for the products); $\varepsilon$ is the molar absorbance of the complex at the wavelength of irradiation $\left(\mathrm{dm}^{3} \mathrm{~mol}^{-1} \mathrm{~cm}^{-1}\right) ; l$ is the optical path length of the cuvette $(\mathrm{cm}) ; \Delta A / \Delta t$ is the change of absorbance over time.

25 The initial slope method does not take the degradation of the complex (thus, its decreasing absorbance) over the whole irradiation time into account, instead it uses predominantly the first measurement points in the calculation. The former equation (Eq. 4) is simplified to:

30

$I_{0} \Phi \varepsilon l\left(1-10^{-A_{0}}\right) t=A_{0}-A$

where $A_{0}$ is the initial absorbance of the irradiated solution at the given wavelength. If we are to take all the measurements points 35 into consideration, we can use a differential equation that counts with the continuous decrease in absorption at the irradiation wavelength:

$\Phi \int_{0}^{t} \mathrm{~d} t=-\frac{1}{I_{0} \varepsilon l} \times \int_{A_{0}}^{A} \frac{1}{1-10^{-A}} \mathrm{~d} A$

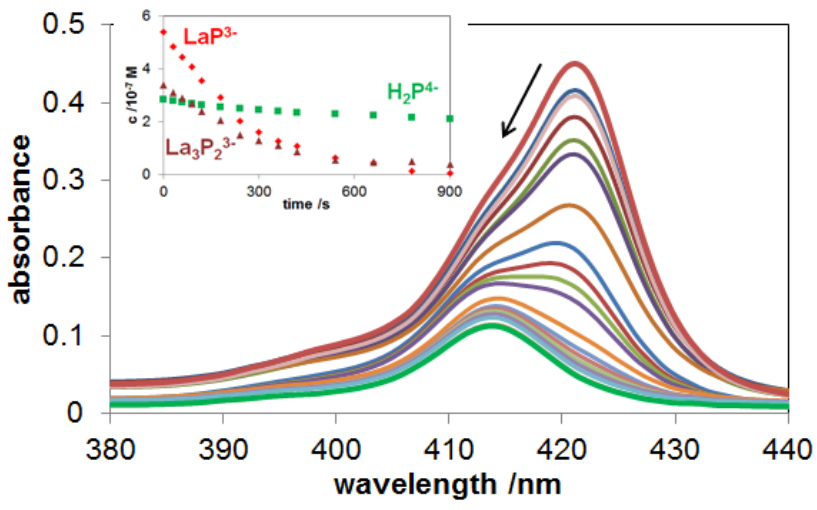

Fig. 13 Spectral changes during the Soret-band irradiation of solution containing $1.40 \times 10^{-6} \mathrm{M} \mathrm{H}_{2} \mathrm{TSPP}^{4-}, 6.4 \times 10^{-6} \mathrm{M} \mathrm{La}^{3+}$, and $0.01 \mathrm{M}$ chloride. $\left(\mathrm{pH} \approx 6, I_{0}(421 \mathrm{~nm})=1.44 \times 10^{-5} \mathrm{M}\right.$ photon $\left./ \mathrm{s}, \ell=1 \mathrm{~cm}\right)$. Inset: concentrations $v s$. irradiation time plots of the light-absorbing species.

$$
\Phi t=\frac{A_{0}-A+\lg \frac{1-10^{-A_{0}}}{1-10^{-A}}}{I_{0} \varepsilon l}
$$

Here the logarithmic expression can be thought of as the correction of the initial slope method. This method can be used to determine if there is really only one absorbing species and if the 45 photochemical process is only dependent on the concentration of the complex. If the right side of the equation is plotted against the measurement time $t$, then the linear diagram should start from the origin and its slope should coincide with the overall photochemical quantum yield. If, however, the diagram is not linear, the 50 simplifications of the initial slope method cannot be used. As Fig. 11 indicates, this is the case in our system.

Here the initial linear section of the plot (the first $400 \mathrm{~s}$ in Fig. 11) can be used for determination of the quantum yield (which is the slope of this linear section). Deviation from the linearity can 55 also be caused by a new species formed in the photoinduced reaction the absorbance of which becomes considerable at the irradiation wavelength. This is the so-called inner filter effect. Such a species in our case can be the free-base porphyrin released in photodissociation of the complex. Besides, subsequent dark 60 reactions of the excited species can result in deviation from the linearity. In order to examine this possibility, an evaluation taking the actual concentrations of the light-absorbing components of the system into account was applied. Eq. 8 was used for determination of the actual concentrations in our system containing acetate ions.

65

$$
\begin{aligned}
& A_{t}=A((A c) L a P)_{t}+A\left(H_{2} P\right)_{t}= \\
& =\varepsilon((A c) L a P) \times\{(A c) L a P\}_{t} \times 1+\varepsilon\left(H_{2} P\right) \times\left\{H_{2} P\right\}_{t} \times 1
\end{aligned}
$$

The concentration $v s$. time plots obtained in this way are shown in Fig. 12.

70

Using this method, also the distribution of the light absorbed by these components is calculated. Eq. 9 expresses the light absorbed by the $i$ th species from $n$ absorbing ones. 


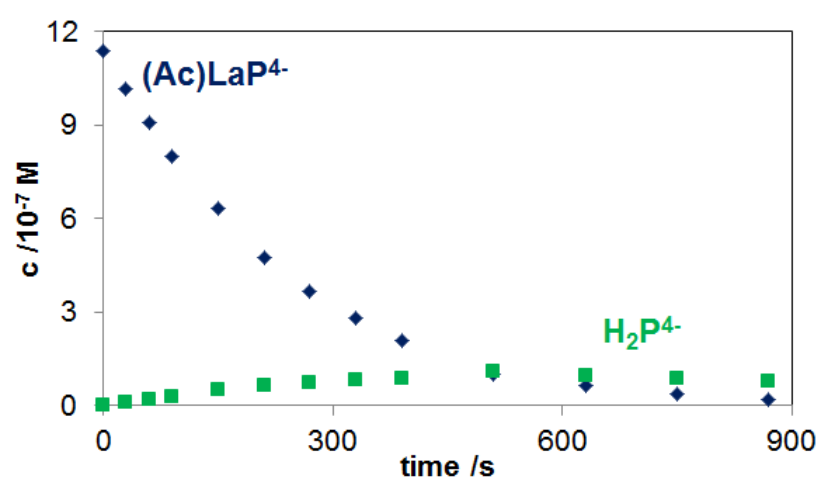

Fig. 12 The concentration $v s$. time plots of the light-absorbing species in the experiment evaluated by the integral fitting method in Fig. 11.

$$
I_{i}=I_{0} \times\left(1-10^{-A_{0}}\right) \times \frac{1-10^{-A_{i}}}{n-\sum_{j=1}^{n} 10^{-A_{j}}}
$$

Thus, individual quantum yields can be determined for the photoinduced reactions of these particular species.

Irradiations were also carried out with solutions of constant 5 lanthanum(III) concentration, but with various porphyrin concentrations. The goal of these experiments was to find the reason of the deviation from the linearity of the plot obtained by the integral fitting method. The quantum yields obtained by all the three evaluation methods are summarized in Table 6.

10

The results clearly show that the quantum yields (both the overall obtained by the initial slope and the integral fitting methods and the individual regarding the $(\mathrm{Ac}) \mathrm{LaP}^{4-}$ species) are enhanced upon increasing the porphyrin concentration. This phenomenon

Table 6 The quantum yields in the system containing acetate $(0.01 \mathrm{M})$, determined by various evaluation methods.

\begin{tabular}{|c|c|c|c|c|}
\hline $\begin{array}{l}\text { c(porph) } \\
/ 10^{-6} \mathrm{M}\end{array}$ & $\begin{array}{c}\text { initial } \\
\text { slope } \\
/ 1^{-4}\end{array}$ & $\begin{array}{c}\text { integral } \\
\text { fitting } \\
/ 10^{-4}\end{array}$ & $\Phi \underset{/ 10^{-4}}{(\mathbf{A c}) \mathbf{L a P}^{4-}}$ & $\begin{array}{c}\% \\
(\mathrm{Ac}) \mathrm{LaP}^{4} \\
\text { redox }\end{array}$ \\
\hline 0.7 & 2.1 & 2.0 & 2.1 & $89 \%$ \\
\hline 1.5 & 4.3 & 3.9 & 4.8 & $87 \%$ \\
\hline 2.9 & 4.4 & 4.3 & 5.4 & $89 \%$ \\
\hline 4.4 & 5.2 & 5.1 & 6.0 & $86 \%$ \\
\hline
\end{tabular}

${ }^{\mathrm{a}} \Phi$ is the overall photochemical quantum yield observed in Soret-band photolysis, and "\% redox"denotes fraction of the photoinduced redox reaction in the overall quantum yield, beside the photoinduced dissociation.

15 suggests that bimolecular excited state (excimer formation), or dark reactions following the excitations, or the primary photochemical steps involve ground-state lanthanum(III) porphyrin complexes. This is in accordance with the observation ${ }^{52}$ that the oxidized ligand (radical) reacts further, through several 20 redox steps, forming its final open-chain bilindion derivative. Beside the quantum yields for the disappearance of the complex $\left((\mathrm{Ac}) \mathrm{LaP}^{4-}\right)$, the percentage of its redox degradation is also given in Table 6. The data indicate that the ratio of the redox process, and, thus, that of the photodissociation (the other photoinduced
25 process contributing to the disappearance of $\left.(\mathrm{Ac}) \mathrm{LaP}^{4-}\right)$ is practically constant, independently of the porphyrin concentration. This tendency suggests that the efficiencies of these two competitive processes are similarly affected by the porphyrin concentration. Formation and decay of an exciplex with 2:2 30 composition may be involved in these reactions. This assumption is in accordance with the observation that the $\pi-\pi$ interaction in the $\pi \pi^{*}$ excited state is much larger than that which occurs in the ground state. ${ }^{62}$

Since in the presence of chloride ions $(0.01 \mathrm{M})$, at the applied 35 concentrations of $\mathrm{H}_{2} \mathrm{TSPP}^{4-}$ and $\mathrm{La}(\mathrm{III})$, mono- and bisporphyrin complexes exist in equilibrium in our aqueous system. The wavelengths of their absorption maxima are very close (Fig. 7), hence both are efficiently excited upon irradiation at the Soretbands. Consequently, neither the initial slope, nor the integral 40 fitting method can be applied for the evaluation of the spectral changes recorded during the irradiation of this system. However, using the calculation of the individual concentration of each lightabsorbing species, it turned out that even free-base porphyrin is present in these solutions in appreciable concentration (Fig. 13), 45 which is in accordance with the formation constant $\lg /{ }^{\prime}{ }_{1: 1}=3.3$ being significantly lower than that in the presence of acetate ions $\left(\lg /{ }^{\prime}{ }_{1: 1}=3.8\right)$ at the same ionic strength $(0.01 \mathrm{M})$.

As shown in Fig. 13, deviating from the system containing acetate ions, no increase in the concentration of the free-base 50 porphyrin was observed during the irradiation; moreover, it continuously decreased, although much slower than those of the complexes $\left(\mathrm{LaP}^{3-}\right.$ and $\left.\mathrm{La}_{3} \mathrm{P}_{2}{ }^{3-}\right)$. However, we could not exclude the change of the equilibrium in the photostationary state, because the stabilities of the complexes in this state may differ from those in 55 the ground state. Thus, all possible transformations of the three porphyrin species to each other (even to exciplex) as well as their decomposition were taken into account in Eqs. 10-13 expressing the reaction rate of $\mathrm{LaP}, \mathrm{La}_{3} \mathrm{P}_{2}$ and $\mathrm{H}_{2} \mathrm{P}$, respectively:

$$
\begin{aligned}
\mathrm{d}\{\mathrm{LaP}\} / \mathrm{dt} & =\mathrm{v}(\mathrm{LaP} \text { redox })+\mathrm{v}\left(\mathrm{LaP} \rightarrow \mathrm{H}_{2} \mathrm{P}\right)+ \\
+ & \mathrm{v}\left(\mathrm{LaP} \rightarrow \mathrm{La}_{3} \mathrm{P}_{2}\right)-\mathrm{v}\left(\mathrm{La}_{3} \mathrm{P}_{2} \rightarrow \mathrm{LaP}\right) \\
\mathrm{d}\left\{\mathrm{La}_{3} \mathrm{P}_{2}\right\} / \mathrm{dt} & =\mathrm{v}\left(\mathrm{La}_{3} \mathrm{P}_{2} \text { redox }\right)+\mathrm{v}\left(\mathrm{La}_{3} \mathrm{P}_{2} \rightarrow \mathrm{LaP}\right)+ \\
& +\mathrm{v}\left(\mathrm{La}_{3} \mathrm{P}_{2} \rightarrow \mathrm{H}_{2} \mathrm{P}\right)-\mathrm{v}\left(\mathrm{LaP} \rightarrow \mathrm{La}_{3} \mathrm{P}_{2}\right) \\
\mathrm{d}\left\{\mathrm{H}_{2} \mathrm{P}\right\} / \mathrm{dt} & =\mathrm{v}\left(\mathrm{H}_{2} \mathrm{P} \text { redox }\right)+\mathrm{v}\left(\mathrm{H}_{2} \mathrm{P} \rightarrow \mathrm{La}_{\mathrm{x}} \mathrm{P}_{\mathrm{y}}\right)- \\
& -\mathrm{v}\left(\mathrm{LaP} \rightarrow \mathrm{H}_{2} \mathrm{P}\right)-\mathrm{v}\left(\mathrm{La}_{3} \mathrm{P}_{2} \rightarrow \mathrm{H}_{2} \mathrm{P}\right)
\end{aligned}
$$

$\mathrm{d}\{$ total porph. $\} / \mathrm{dt}=\mathrm{v}(\mathrm{LaP}$ redox $)+\mathrm{v}\left(\mathrm{La}_{3} \mathrm{P}_{2}\right.$ redox $)+$

$$
+\mathrm{v}\left(\mathrm{H}_{2} \mathrm{P} \text { redox }\right)
$$

Irradiations were carried out, also in this case, with solutions of constant $\mathrm{La}(\mathrm{III})$ concentration, but with various porphyrin concentrations. Similarly to the system containing acetate ions, the ${ }_{65}$ quantum yields were enhanced upon increasing the porphyrin concentration (Table 7).

Table 7 The individual quantum yields of the light-absorbing species at various porphyrin concentrations in the system containing chloride ions 


\begin{tabular}{|c|c|c|c|c|c|}
\hline $\begin{array}{c}\text { c(porph) } \\
/ 10^{-6} \mathrm{M}\end{array}$ & $\begin{array}{c}\Phi \mathrm{LaP}^{3-} \\
/ 10^{-4}\end{array}$ & $\begin{array}{l}\% \mathrm{LaP}^{3-} \\
\text { redox }\end{array}$ & $\begin{array}{c}\Phi \mathrm{La}_{3} \mathbf{P}_{2}{ }^{3-} \\
/ 10^{-4}\end{array}$ & $\begin{array}{c}\% \mathrm{La}_{3} \mathbf{P}_{2}{ }^{6-} \\
\text { redox }\end{array}$ & $\begin{array}{c}\mathrm{H}_{2} \mathrm{P}^{4-} \\
/ \mathbf{1 0}^{-4}\end{array}$ \\
\hline 0.75 & 2.5 & $63 \%$ & 0.64 & $42 \%$ & 0.20 \\
\hline 1.4 & 3.8 & $52 \%$ & 3.2 & $48 \%$ & 0.40 \\
\hline 2.3 & 5.3 & $51 \%$ & 4.1 & $50 \%$ & 0.84 \\
\hline 3.0 & 8.5 & $43 \%$ & 7.5 & $53 \%$ & 1.6 \\
\hline 4.5 & 13 & $42 \%$ & 12 & $52 \%$ & 2.8 \\
\hline
\end{tabular}

Since no increase in the concentration of the free-base porphyrin was observed upon excitation of this system, the number of the 5 metal ions in the bisporphyrin cannot be fewer than that of the porphyrin ligands. Besides, about $50 \%$ of the overall quantum yield can be attributed to redox reactions for both the mono- and the bisporphyrins. Thus, similar contribution is represented by dissociation, interconversion including exciplex or excimer 10 formation. Upon increasing the porphyrin concentration, the fraction of this contribution increased for the mono- and decreased for the bisporphyrins. These tendencies may also, at least partly, interpreted by the $\pi-\pi$ interactions, for which $1: 1$ composition is more favorable than $3: 2$. In the case of the latter complex the 15 porphyrin ligands are shielded by the two outer metal ions hindering $\pi \pi$ interactions with another complex or a free base.

\section{Conclusions}

Lanthanum(III), due to its large ionic radius, cannot fit into the cavity of a porphyrin ligand, and, thus, it is located out of the ligand ${ }_{20}$ plane as proved by spectral evidences and theoretical calculations

1 C.K. Mathews, K.E. van Holde, K.G. Ahern, Biochemistry, Addison Wesley Longman, San Francisco, 2000.

2 R.H. Garrett, C.M. Grisham, Biochemistry, Saunders College Publishing, 1999.

3 G. Knör and A. Strasser, Inorg. Chem. Commun., 2005, 9, 471-473.

4 M.D. Lim, I.M. Lorkovic and P.C. Ford, J. Inorg. Biochem., 2005, 99, 151-165.

5 G.G. Martirosyan, A.S. Azizyan, T.S. Kurtikyan and P.C. Ford, Chem. Commun., 2004, 1488-1489.

6 A.G.Tovmasyan, N.S. Babayan, L.A. Sahakyan, A.G. Shahkhatuni, G.H.Gasparyan, R.M. Aroutiounian and R.K. Ghazaryarn, J. Porphyr. Phthalocya., 2008, 12, 1100-1110.

7 Q.G. Ren, X.T. Zhou and H.B. Ji, Chinese J. Org. Chem., 2010, 30, 1605-1614.

8 K. Kawamura, S. Igarashi, and T. Yotsuyanagi, Microchim. Acta, 2011, 172, 319-326.

9 E.B. Fleischer and J.H. Wang, J. Am. Chem. Soc., 1960, 82, 3498-3502.

10 K.M. Barkigia, J. Fajer, A.D. Adler and G.J.B. Williams, Inorg. Chem., 1980, 19, 2057-2061.

11 M.S. Liao, J.D. Watts and M.J. Huang, J. Phys. Chem., A, 2006, 110, 13089-13098.

12 V.E.J. Walker, N. Castillo, C.F. Matta and R.J. Boyd, J. Phys. Chem., A, 2010, 114, 10315-10319.

13 M. Tabata and M. Tanaka, J. Chem. Soc., Chem. Comm., 1985, 42-43.

14 M. Tabata, W. Miyata and N. Nahar, Inorg. Chem., 1995, 34, 64926496.

15 C. Grant and P. Hambright, J. Am. Chem. Soc., 1969, 91, 4195-4197.

16 L.R. Robinson and P. Hambright, Inorg. Chem., 1992, 31, 652-656.

17 C. Stinson and P. Hambright, J. Am. Chem. Soc., 1977, 99, 2357.

18 K.M. Barkigia, M D. Berber, J.Fajer, C.J. Medforth, M.W. Renner and K.M. Smith, J. Am. Chem. Soc., 1990, 112, 8851-8857.

19 J.Y. Tung and J.-H. Chen., Inorg. Chem., 2000, 39, 2120-2124.

20 O. Horváth, R. Huszánk, Z. Valicsek and G. Lendvay, Coord. Chem. Rev., 2006, 250, 1792-1803. as well. Hence, this metal center of high coordination number can bind another porphyrin ligand, forming bisporphyrin as observed in the presence of chloride ions. The axially stronger coordinating acetate ion hinders this process. The distorted structure, in the 25 cases of both mono- and bisporphyrins, promotes demetalation and irreversible ring-cleavage following the photoinduced charge transfer from the porphyrin ligand to the metal center, especially in aqueous solution, as demonstrated with lanthanide(III) porphyrins for the first time in this work. Although 30 photodissociation as a minor reaction takes also place with the monoporphyrin, the photoinduced LMCT process is more important because it may be utilized for water-splitting, due to the extreme redox potential of the lanthanide(II) ion formed. Further studies are in progress with water-soluble porphyrins of other rare ${ }_{35}$ earth metal ions such as $\mathrm{Ce}(\mathrm{III}), \mathrm{Nd}(\mathrm{III})$, and $\mathrm{Sm}(\mathrm{III})$.

\section{Acknowledgements}

This work was supported by the Hungarian Scientific Research Fund (OTKA No. K101141) and the Hungarian Government and the European Union, with the co-funding of the European Social ${ }_{40}$ Fund (TÁMOP 4.2.2/B-10/1-2010-0025).

\section{Notes and references}

${ }^{a}$ Department of General and Inorganic Chemistry, Institute of Chemistry, University of Pannonia, Veszprém, P.O. Box 158. , H-8201 Hungary. Fax: +368862 4548; Tel: 368862 4159;

45 E-mail: otto@mk.uni-pannon.hu 
21 C. P. Wong, R.F. Venteicher and W.D. Horrocks Jr., J. Am. Chem. Soc., 1974, 96, 7149-7150.

22 (a) W. D. Horrocks Jr. and C.P. Wong, J. Am. Chem. Soc., 1976, 98, 7157-7162; (b) W. D. Horrocks Jr. and E.G. Hove, J. Am. Chem. Soc., 1978, 100, 4386-4392.

23 F. W. Oliver, C. Thomas, E. Hoffman, D. Hill, T. P. G. Sutter, P. Hambright, S. Haye, A. N. Thorpe, N. Quoc, A. Harriman, P. Neta and S. Mosseri, Inorg. Chim. Acta, 1991, 186, 119-124.

24 W.-K Wong., X. Zhua and W.-Y. Wong, Coord. Chem. Rev., 2007, 251, 2386-2399, and references therein.

25 V. Bulach, F. Sguerra and M.W. Hosseini, Coord. Chem. Rev., in press (http://dx.doi.org/10.1016/j.ccr.2012.02.027)

26 G. Ricciardi, A. Rosa, E. J. Baerends and S. A. J. van Gisbergen, J. Am. Chem. Soc., 2002, 124, 12319-12334.

27 J. K. Duchowski and D.F. Bocian, J. Am. Chem. Soc., 1990, 112, $8807-$ 8811.

28 L. L. Wittmer and D. Holten, J. Phys. Chem., 1996, 100, 860-868.

29 F.D. 'Souza, G.R. Deviprasad and M.E. Zandler, J. Chem. Soc. Dalton Trans., 1977, 3699-3703.

30 J.N. Demas and G.A. Crosby, J. Phys. Chem., 1971, 75, 991-1024.

31 J. Van Houten and R.J. Watts, J. Am. Chem. Soc., 1976, 98, 4853-4858.

32 J. F. Rabek, Experimental methods in photochemistry and photophysics; Wiley-Interscience publication, John Wiley \& Sons Ltd., New York, 1982.

33 A.D. Kirk and C. Namasivayam, Anal. Chem., 1983, 55, 2428-2429.

34 A.D. Becke, J. Chem. Phys., 1993, 98, 1372-1377.

35 A. D. Becke J. Chem. Phys, 1993, 98, 5648-5652.

36 C. Lee, W. Yang and R.G. Parr, Phys. Rev., B, 1988, 37, 785-789.

37 P. J. Hay and W.R. Wadt, J. Chem. Phys., 1985, 82, 270-283.

38 W. R. Wadt and P.J. Hay, J. Chem. Phys., 1985, 82, 284-298.

39 P. J. Hay and W.R. Wadt, J. Chem. Phys, . 1985, 82, 299-310.

40 Gaussian 03, Revision E.01, M.J. Frisch, G.W. Trucks, H.B. Schlegel, G.E. Scuseria, M.A. Robb, J.R. Cheeseman, J.A. Montgomery, Jr., T. Vreven, K.N. Kudin, J.C. Burant, J.M. Millam, S.S. Iyengar, J. Tomasi, V. Barone, B. Mennucci, M. Cossi, G. Scalmani, N. Rega, G.A. Petersson, H. Nakatsuji, M. Hada, M. Ehara, K. Toyota, R. Fukuda, J. Hasegawa, M. Ishida, T. Nakajima, Y. Honda, O. Kitao, H. Nakai, M. Klene, X. Li, J.E. Knox, H.P. Hratchian, J.B. Cross, V. Bakken, C. Adamo, J. Jaramillo, R. Gomperts, R.E. Stratmann, O. Yazyev, A.J. Austin, R. Cammi, C. Pomelli, J.W. Ochterski, P.Y. Ayala, K. Morokuma, G.A. Voth, P. Salvador, J.J. Dannenberg, V.G. Zakrzewski, S. Dapprich, A.D. Daniels, M C. Strain, O. Farkas, D.K. Malick, A.D. Rabuck, K. Raghavachari, J.B. Foresman, J.V. Ortiz, Q. Cui, A.G. Baboul, S. Clifford, J. Cioslowski, B.B. Stefanov, G. Liu, A.
Liashenko, P. Piskorz, I. Komaromi, R.L. Martin, D.J. Fox, T. Keith, M.A. Al-Laham, C.Y. Peng, A. Nanayakkara, M. Challacombe, P.M.W. Gill, B. Johnson, W. Chen, M.W. Wong, C. Gonzalez and J.A. Pople, Gaussian, Inc., Wallingford CT, 2004.

41 Z. Valicsek and O. Horváth, Microchem. J., in press, 2012 doi:10.1016/j.microc.2012.07.002

42 R.D. Shannon, Acta Cryst., 1976, A32, 751-767.

43 Y.Bian, L. Rintoul, D. P. Arnold, R. Wang and J. Jiang, Vibr. Spect., 2003, 31, 173-185.

44 Z. Valicsek, G. Lendvay and O. Horváth, J. Phys. Chem., B, 2008, 112, 14509-14524.

45 Z. Valicsek, O. Horváth, G. Lendvay, I. Kikaš and I. Škorić, J. Photoch. Photobio., A, 2011, 218, 143-155.

46 Z. Valicsek, O. Horváth and K. Patonay, J. Photoch. Photobio., A, 2011, 226, 23-35.

47 Z. Valicsek, G. Lendvay and O. Horváth, J. Porph. Phthal., 2009, 13, 910-926.

48 J. L. Sessler, T. D. Mody, G. W. Hemmi and V. Lynch, Inorg. Chem., 1993, 32, 3175-3187.

49 J. Lisowski, J. L. Sessler, V. Lynch and T. D. Mody, J. Am. Chem. Soc., 1995, 117, 2273-2285.

50 H. He, W.-K. Wong, J. Guo, K.-F. Li, W.-Y.Wong, W.-K. Lo and K.W. Cheah, Inorg. Chim. Acta, 2004, 357, 4379-4388.

51 Z. Valicsek, M. P. Kiss, Cs. Szentgyörgyi and O. Horváth, unpublished results.

52 Z. Valicsek and O. Horváth, J. Photoch. Photobio., A, 2007, 186, 1-7.

53 R. Huszánk and O. Horváth, Chem. Commun., 2005, 224-226.

54 R. Huszánk, G. Lendvay and O. Horváth, J. Bioinorg. Chem., 2007, 12, 681-690.

55 Z. Valicsek, O. Horváth and K.L. Stevenson, Photochem. Photobiol. Sci., 2004, 3, 669-673.

56 S. J. Strickler and R.A. Berg, J. Chem. Phys., 1962, 37, 814-822.

57 X. Yan and D. Holten, J. Phys. Chem., 1988, 92, 409-414.

58 K. M. Smith and J. J. Lai, Tetrahedron Lett., 1980, 21, 433-436.

59 K. M. Smith, S. B. Brown, R. F. Troxler and J. J. Lai, Tetrahedron Lett. 1980, 21, 2763-2766.

60 B. Evans, K. M. Smith and J. A. S. Cavaleiro, J. Chem. Soc., Perkin I, 1978, 768-773.

61 O. Horváth, Z. Valicsek and A. Vogler, Inorg. Chem. Commun., 2004, 7, 854-857.

62 J.-H. Perng, J. K. Duchowski and D.F. Bocian, J. Phys. Chem., 1991, 95, 1319-1323. 